Chapman University

Chapman University Digital Commons

Accounting Faculty Articles and Research

Accounting

4-15-2013

\title{
Innovators and Imitators in Product-Market Competition and Accounting Reporting
}

Carlos Corona

Carnegie Mellon University

Lin Nan

Purdue University

Ran Zhao

ChapmanUniversity, rzhao@chapman.edu

Follow this and additional works at: https://digitalcommons.chapman.edu/accounting_articles

Part of the Business Administration, Management, and Operations Commons, Business $\underline{\text { Intelligence Commons, Organizational Behavior and Theory Commons, and the Other Business }}$ Commons

\section{Recommended Citation}

Corona, Carlos; Nan, Lin; and Zhao, Ran, "Innovators and Imitators in Product-Market Competition and Accounting Reporting" (2013). Accounting Faculty Articles and Research. 13.

https://digitalcommons.chapman.edu/accounting_articles/13

This Article is brought to you for free and open access by the Accounting at Chapman University Digital Commons. It has been accepted for inclusion in Accounting Faculty Articles and Research by an authorized administrator of Chapman University Digital Commons. For more information, please contact laughtin@chapman.edu. 


\section{Innovators and Imitators in Product-Market Competition and Accounting Reporting}

Comments
Working paper

This article is available at Chapman University Digital Commons: https://digitalcommons.chapman.edu/accounting_articles/13 


\title{
Innovators and Imitators in Product-Market Competition and
}

\section{Accounting Reporting}

\author{
Carlos Corona \\ Carnegie Mellon University
}

\author{
Lin Nan \\ Purdue University
}

April 15, 2013

\author{
Pu
}

\begin{abstract}
In this study, we examine firms' investments in explorative initiatives and their choices of capitalization method in a product-market competition setting. Since the capitalization of exploration expenditures may contain information on whether a firm's exploration investment is successful, financial reports may reveal important information to competitors, and thus may have real consequences in product-market competition. In our paper, we identify two driving forces that induce firms to choose different capitalization methods: an information-spillover effect and a preempting effect. We also find that enforcing an accounting method that requires firms to capitalize expenditures of only successful explorations may increase or decrease innovation investments. Our study sheds light on the impact that the recognition of exploratory success has on firms' exploration investments.
\end{abstract}

\section{Introduction}

In this paper, we study how different accounting methods of capitalization affect firms' explorationinvestment decisions and how firms choose between these capitalization methods when given discre- 
tion. Because the capitalization of exploration expenditures may contain information on whether a firm succeeds in its exploration investment, financial reports may reveal important information to competitors. This information can potentially be used by competitors to imitate the innovative firm's investments, and therefore may substantially affect the firm's ability to compete in the future. Consequently, the capitalization method prescribed by the accounting regime and the capitalization method firms choose when given discretion can potentially affect the firms' exploration-investment decisions in a competitive environment. In our paper, we identify two driving forces that induce firms to choose a capitalization method: an information spillover effect and a preempting effect. We also find that enforcing an accounting method that requires firms to capitalize expenditures of only successful exploration may induce them to invest more or less, depending on their size and the size of their competitors. Our study sheds light on the accounting choices of firms when given discretion regarding capitalization methods and on the impact of accounting regulations on firms' exploration investments and competition.

The oil and gas industry is subject to accounting regulations regarding the recognition of exploration costs for oil and gas reserves. Oil and gas companies can currently choose between the full-cost method and the successful-efforts method to recognize their exploratory costs. If a company chooses the full-cost method, it capitalizes all of its exploration costs, including dry-hole costs. If a company chooses the successful-efforts method, it expenses the exploration costs that are related to unsuccessful exploration, and capitalizes only the expenditures related to successful exploration. It is well documented that large oil and gas companies more often use the successfulefforts method, while smaller companies choose the full-cost method (Sunder, 1976; Deakin, 1979; Dhaliwal, 1980; Bryant, 2003). The difference in the choices made by large and small oil and gas companies is usually explained by the argument that small firms cannot afford the earnings volatility induced by the successful-efforts method, because it would make it harder for small firms 
to obtain capital if they expensed their unsuccessful exploration costs. However, this argument implies that the market cannot see through this earnings volatility. That is, it implies that the market is not completely efficient. Our model provides an alternative explanation for the difference in preferences over capitalization methods that does not rely on market inefficiency.

In this paper, we examine a duopolistic setting in which firms have the option to choose between the full-cost and successful-efforts methods to capitalize their exploration expenditures. In our model, an innovator firm moves first to choose its accounting method and decide its investment in explorative activities. The other firm, which we call the imitator, moves later, deciding its investing strategy after observing the accounting report issued by the innovator firm. ${ }^{1}$ After the outcomes of both firms' investments are realized, the two firms compete in a product market. Our analysis shows that if the innovator is a small firm, it is more concerned about information spillover and tends to choose the full-cost method; on the other hand, if the innovator is a large firm, ex ante it may prefer to use the successful-efforts method so that it will be able to secure its preemptive advantage by disclosing its success.

We also examine the consequences of enforcing a uniform capitalization method on firms' exploration-investment choices. The question of whether firms should be granted the option of choosing between different accounting-recognition methods for exploration expenditures has been debated for decades. In 1977, the Financial Accounting Standards Board (FASB) proposed the Statement of Financial Accounting Standards No. 19 to remove the option of the full-cost method in the oil and gas industry. However, the proposal encountered great resistance and was not enacted. Recently, this debate resurfaced again as the International Accounting Standards Committee (IASC) initiated a project to eliminate the full-cost method for extractive industries in 1998 (International Accounting Standards Committee 2000a). Again, the attempt to eliminate the full-cost

\footnotetext{
${ }^{1}$ Although we call the second mover in our model the "imitator" for convenience, the imitator may decide not to imitate the innovator's investments.
} 
method failed, and the final outcome of this project, International Financial Reporting Standard 6, still allows the choice between accounting methods. The elimination of the full-cost method raises many concerns from both extractive-industry practitioners and academicians. One reason in particular to oppose this proposed change is that the elimination of the full-cost method will hinder small firms' access to capital markets, and therefore prevent those firms from undertaking innovative investments (Collins and Dent, 1979). However, our analysis shows that small firms may invest more in innovative activities if the successful-efforts method is enforced. This is because under this regime, firms with information-spillover concerns may choose to invest more to dilute the information content in their financial reports. Also, we find that if the full-cost method is enforced, firms may invest less in their exploration activities. With the full-cost method, although an innovator firm is not concerned about information-spillover repercussions, it nevertheless loses a means of threatening its rival through the reporting of its successful exploration. As a consequence, the firm may reduce its innovative investment.

The rest of the paper is organized as follows: Section 2 provides a review of previous studies that are relevant to our paper. In Section 3, we describe and analyze the main setting of our paper, in which firms have the option to choose between the full-cost and successful-efforts methods and the innovator is a relatively large firm. In Section 4, we examine a setting in which only the successful-efforts method is allowed and a setting in which firms can only use the full-cost method. In Section 5, for completeness, we provide the analysis of an alternative setup in which the imitator firm is relatively large. Section 6 concludes the paper.

\section{$2 \quad$ Literature Review}

Our study is related to studies on the effect of accounting disclosure in product market competition. Darrough and Stoughton (1990) and Feltham and Xie (1992) examine the incentive firms have to 
disclose or withhold private information in an entry game, and they illustrate a tension between an informed manager's desire to communicate good news to (and hide bad news from) the capital market and his desire to communicate bad news to (and hide good news from) competitors in the product market. Arya and Mittendorf (2007) illustrate how firms' incentives to withhold private information from competitors are undercut by the fact that disclosures also boost analyst following, which provides firms with new information about market conditions. Bagnoli and Watts (2010) examine a Cournot competition setting in which firms can misreport their production costs. In this study, we concentrate more on a tension between a desire to hide proprietary information to deter rivals from imitating and a desire to disclose information to rivals to achieve a preemptive advantage.

There are numerous empirical studies on the debate of whether extraction industries should keep the option of choosing between the successful-efforts and full-cost methods. Some studies indicate that the successful-efforts method is more informative. For example, Harris and Ohlson (1987) show that the book values of firms using the successful-efforts method have higher explanatory power about their market values than those of firms using the full-cost method. Bandyopadhyay (1994) compares the earnings-response coefficients of successful-efforts firms and full-cost firms around the announcement of quarterly earnings over the 1982-1990 period, and finds that successful-efforts firms have higher coefficients. There are also studies that shed light on how different choices of accounting methods may influence firms' investment in exploration activities. For example, Johnson and Ramanan (1988) examine the oil and gas industry during 1970-1976 and find that firms that switch to the full-cost method exhibit higher level of exploration activities and higher leverage. Lilien and Pastena (1982) find that revenues are positively associated with the successful-efforts choice, while leverage and exploratory aggressiveness are positively correlated with the full-cost choice. Despite the abundance of empirical research in this area, there are few analytical studies 
on the cost and benefit of keeping the discretion between different methods regarding extractive industries' exploration expenditures. We contribute to this line of literature by providing analytical insights on this debate.

Our study is also related to studies on the aggregation in information disclosures. Arya, Frimor, and Mittendorf (2010) study the discretionary disclosure of proprietary information by multi-segment firms. They show that a disaggregate report may convey high cost in some markets to soften rival competition, but at the same time inevitably convey low cost in the other markets and induce fiercer competition. As a result, they find that the optimal disclosure aggregates segment details. In our paper, aggregation is not across segments, but across successful and unsuccessful investments in the same market. As a result, our paper does not need to rely on multiple markets to show the effects of disclosure aggregation. Instead, we show that firms choose between less aggregated or more aggregated disclosure policies depending on their relative size to competitors and the severity of the information spillover. Hayes and Lundholm (1996) examine a firm's disclosure of segment details when facing both a capital market and a product market, and show that the firm may withhold information when the product market concerns are sufficiently pronounced. In our paper, capital markets do not play a role. Instead, the product market is at center stage, and aggregation is instrumental in reducing the information spillover to competitors.

\section{The Main Model}

\subsection{Setup}

We consider a setting in which there are two firms, A and B, that compete in a Cournot duopoly product market. Before the firms compete in the product market, however, they can make exploration investments that, when successful, improve their ability to compete. We further assume that 
firms invest sequentially. In particular, firm A decides first on its exploration investments, and once the investments outcomes are realized, firm A issues a public accounting report. After observing firm A's accounting report, firm B decides on its own investments. Firm B's decision on whether to imitate firm A's innovation depends on how much information firm B is able to obtain before deciding on its own exploration investments. This information is determined in part by the accounting report issued by firm $\mathrm{A}$, and therefore by the accounting regulatory regime. This sequence of events allows us to examine both the endogenous accounting choices of innovating firms and the effect of accounting regulation on exploratory investments taking into account the resulting spillover of information in a competitive environment. We often refer to firm A as an "innovator" and to firm B as an "imitator." Also, in our analysis and discussion, we use the oil and gas industry as a running example. In this industry, the accounting regulations regarding capital expenditures in exploratory activities have been the subject of frequent debate by both practitioners and researchers. For this reason, it provides us with realistic examples to illustrate our model and analysis. Nevertheless, our analysis can be interpreted in a much broader way and can potentially be applied to a wide set of industries. ${ }^{2}$

We characterize the space of possible exploration initiatives as being subdivided into "areas" of exploration. Depending on the industry, these areas can have a different interpretation. For instance, in the extractive industry an area can be thought of as the proximity of a mining or drilling location; in the pharmaceutical industry an area can be understood as a line of research for a new drug for a specific disease; in the software industry an area might be the sort of application under development, and so forth. Exploration initiatives can be kept more or less confidential depending on the industry, but they can seldom be completely private. We reflect this fact by assuming that competitors can observe the areas in which a firm explores. The extent to which the

\footnotetext{
${ }^{2}$ For example, the software industry also encounters the problem of how to capitalize firms' R\&D expenses, and different accounting recognition rules may have real effects on firms' innovation investments.
} 
observability of explored areas is informative is also contingent on the industry under consideration. In the extractive industry, for instance, knowing the location in which another firm is exploring is potentially very informative. In the software industry, however, knowing what sort of application a firm is developing might be not as useful without more detail. Still, the information of which areas a firm is exploring might be a lot more valuable if the outcome of the exploration is also known. Depending on the accounting regulatory regime and the accounting choices of the reporting firm, the success or failure of exploration initiatives is potentially revealed by the accounting report. Notice that in our paper the innovator and imitator compete in the same market, and the innovator's exploration-outcome disclosure should be relevant to its competitor's decisions in the market competition for similar products.

We assume that there are plenty of exploration "areas" in which firms can invest. We assume that a firm can potentially invest in several areas, and that the exploration outcome in each of these areas is binary: success or failure. We denote the probability of success of an investment in a specific area by $h$, and we assume that $0<h<\frac{1}{3}$. That is, we assume the ex-ante probability of success is not too large so that information about the innovator's success is relevant to the imitator. We also assume that this probability is public information and independent across different areas. To avoid unnecessary complexity in the Bayesian updating, we further assume that if an exploration in an area is successful, then any subsequent exploration in that area is also successful with certainty. For instance, if a firm finds an oil reserve in a certain area, any other firm exploring this same area profits from drilling the same oil reserve. On the other hand, if a firms fails to succeed in exploring an area, other firms also fail when exploring the same area. To reflect the increased competitiveness obtained through a successful exploration, we assume that a success increases the contribution margin per unit of firm A by a quantity $a$, where $0<a<\frac{1}{4} \cdot{ }^{3}$ If firm $\mathrm{B}$ succeeds

\footnotetext{
${ }^{3}$ We assume $a<\frac{1}{4}$ in our model. If $a>\frac{1}{4}$, we can show that the preempting effect will be so overwhelming that B
} 
in exploring a different area, it obtains the same benefit. However, if it explores in an area in which firm A already succeeded, firm B only increases its contribution margin per unit by $\gamma a$, with $0<\gamma<1$. One can think of $\gamma$ as incorporating the fact that the extent to which the success by the innovator can be imitated by the follower varies from industry to industry. For instance, in extractive industries, $\gamma$ may reflect the fact that the first firm that obtains success in exploring a specific area may take the best "spots," while subsequent entrants can only take the leftovers. In a technology industry, $\gamma$ may reflect the fact that the pioneering firm may obtain an advantage in the form of a reputation for innovation or for technical sophistication in the mind of consumers. In this study, we concentrate on cases in which $\gamma$ is not too small by assuming $\gamma>\underline{\gamma}^{4}$ This is because when $\gamma$ is very small, the benefit from imitation is so small that B never wants to imitate A's investment. Because we are interested in B's imitating decision and this case does not bring any additional insight, we rule it out to avoid taxing readers with tedious analysis.

To consider the effect of firm size on accounting discretionary choices and investment decisions, we reflect the size of a firm in the model by assuming that larger firms have a lower cost of investment. This is to reflect the reality that, for example, it is easier for large firms to access capital than for small firms, and large firms may also enjoy the benefit of economies of scale. Regardless of their size, however, we assume that all firms have a convex cost of investment. That is, each additional area is more expensive to explore. We denote firm $i$ 's cost of investing in the $j^{\text {th }}$ area by $k_{j}^{i}$. For instance, the cost of exploring a second area for firm $A$ is $k_{2}^{A}$. The investment-cost convexity then implies that $k_{j}^{i}<k_{j+1}^{i}$. We examine two scenarios. In the main analysis, we examine a scenario in which firm A is large and firm B is small. More specifically, firm A can explore up to two areas. Its first exploration $\operatorname{costs} k_{1}^{A}(>0)$, and its second exploration costs $k_{2}^{A}$, where $k_{2}^{A}>k_{1}^{A}$.

will not invest at all when A discloses no information about its success, which is not an interesting case and provides limited insight compared with our currrent setting.

${ }^{4}$ The derivation of the value of $\underline{\gamma}$ is available in the Appendix. 
Firm B can only invest in up to one area. That is, the cost of investing in one area is $k_{1}^{B}(>0)$, and the cost of investing in a second area is $\infty$. Later in Section 5, we examine the opposite situation, a scenario in which firm $\mathrm{A}$ is small and firm B is large.

In the main analysis, we assume the cost is not too large to preempt firms from investing. The reason is that if B's cost is so high that it chooses not to invest when it does not obtain any information from A's report, then A will always choose not to disclose any information about its outcome, so that B will not have a chance to get the increase in its contribution margin. To focus on interesting cases that B will invest even without any information of A's outcome, we assume $k_{1}^{i}<\bar{K}=\frac{4 a h(1+a-2 a h)}{9}$ from now on. ${ }^{5}$ With this assumption, A will always invest in at least one innovative investment and B will not be completely discouraged from making an investment when A invests.

In the oil and gas industry, there has been a long debate regarding the recognition of the cost of exploring for oil and gas reserves. Currently, oil and gas companies can choose between the fullcost method or the successful-efforts method to recognize these costs. These two capitalizations methods are informatively different, and therefore provide us with a case of a specific regulatory choice that potentially affects the amount of information spillover between competing firms. ${ }^{6}$ We examine three regulatory regimes. In this section, we examine the case in which firms are allowed to choose between the two capitalization methods. In Section 4, we examine the consequences of enforcing the successful-efforts method and the consequences of enforcing the full-cost method.

\footnotetext{
${ }^{5}$ The detailed derivation of this threshold is in the Appendix.

${ }^{6}$ Oil and gas firms that use the full-cost method usually do not write off their dry wells separately. When they write off their assets, it is usually difficult to tell whether the write offs are due to dry wells or other assets impairments. However, even if they write off the book value of their dry wells and disclose, which reveals information of the exploration results, write offs usually do not occur in a timely manner and are not useful in competitors' investment-in-exploration decisions.
} 


\begin{tabular}{llll} 
date 1 & date $2 \mid$ & date $3 \mid$ \\
\hline Firm A chooses a & Firm A observes the investment & The outcome of \\
capitalization & outcome and reports. & both firms' investments \\
method and makes its & Firm B makes the investment & is revealed. The two \\
investment decision. & decision after observing A's & firms compete in a \\
& report. & Cournot market.
\end{tabular}

Figure 1: Time line.

We examine a setting with three dates. Figure 1 illustrates the time line. At date 1, firm A chooses whether to use the full-cost or the successful-efforts method, and decides on the area(s) to explore. Firm A's capitalization method and which area(s) it chooses to explore are publicly observable. At date 2, A reports according to its previous choice of accounting method. We denote firm A's report by $D=\left(I_{A}, \widehat{x}_{A}\right)$, where $I_{A} \in\{1,2\}$ is the number of areas that firm A explores, and $\widehat{x}_{A} \in\{0,1,2\} \cup\{\emptyset\}$ is the reported number of areas in which the exploration was successful. Notice that under the successful-efforts method, the accounting report provides information about the aggregate successful investment. In that case, we let $\widehat{x}_{A} \in\{0,1,2\}$ be the number of successful areas of exploration. Obviously, the firm can only succeed in areas in which it invested; i.e., $x_{A} \leq I_{A}$. Under the full-cost method, however, the report does not distinguish between successful and failed exploration investments. That is, under the full-cost method the accounting report provides no new information; i.e., in that case we set $\widehat{x}_{A}=\emptyset$. Firm B observes A's report and makes its own exploration decision by choosing $I_{B} \in\{0, s, d\}$, where $I_{B}=0$ means that firm B does not invest, $I_{B}=s$ means that firm B chooses to explore one of the same areas firm A previously explored, and 
$I_{B}=d$ means that firm $\mathrm{B}$ explores a different area than firm A.

At date 3, the outcomes of both firms' explorations are revealed and both firms compete in a Cournot product market. ${ }^{7}$ That is, we assume that the initial information provided in the accounting reports is timely enough for the imitator to make investment decisions, and that by the time the investment outcomes affect the market competition the outcomes have been fully revealed. We denote the exploration outcome of firm B by $x_{B} \in\{0, \sigma, \delta\}$, where 0 means that either B does not invest or that B's exploration fails, ${ }^{8} \sigma$ means that B succeeds in an area in which A previously succeeded, and $\delta$ means that B succeeds in a different area than the ones explored by A.

The payoff functions of firms A and B are, respectively:

$$
\begin{gathered}
\Pi_{A}=q_{A}\left(1-q_{A}-q_{B}+a_{A}\right)-k_{1}^{A}-k_{2}^{A} \cdot t_{A}, \\
\Pi_{B}=q_{B}\left(1-q_{A}-q_{B}+a_{B}\right)-k_{1}^{B} \cdot t_{B},
\end{gathered}
$$

where $a_{i}$ for $i \in\{A, B\}$ is the change in contribution margin obtained through successful exploration. In particular, $a_{A}=a$ if $\mathrm{A}$ finds oil in one area, $a_{A}=2 a$ if $\mathrm{A}$ finds oil in two areas, $a_{B}=a$ if $\mathrm{B}$ finds oil in a different area than $\mathrm{A}, a_{B}=\gamma a$ if $\mathrm{B}$ finds oil in the same area as $\mathrm{A}$, and $a_{i}$ is zero if firm $i$ 's exploration fails. Also, $t_{A}$ is an indicator variable that equals zero if A explores one area and equals one if $\mathrm{A}$ explores two areas; $t_{B}$ is an indicator variable that is zero if $\mathrm{B}$ does not invest in exploration and equals one if $\mathrm{B}$ explores one area. We denote firm $i$ 's quantity decision by $q_{i}$, and $1-q_{i}-q_{j}+a_{i}$ represents firm $i$ 's contribution margin, $i, j \in\{A, B\}$. The price of the product is decreased by both firm $i$ 's production and the other firm's production, and we assume the products are perfectly substitutable.

\footnotetext{
${ }^{7}$ In the Appendix, we also examine a Bertrand competition and show that our results with a Cournot competition assumption are robust in a Bertrand setting in which successful exploration reduces the innovator's production cost.

${ }^{8}$ Because firm A cannot take advantage of this information in making its investment decisions, these two outcomes are equivalent.
} 


\subsection{Information-Spillover Effect and Preempting Effect}

In this subsection, we will derive the equilibrium of our model and illustrate two effects that influence the equilibrium: the information-spillover effect and the preempting effect. If firm A reports using the successful-efforts method, its accounting report contains information about the outcome of its exploration activities, and its competitors may take advantage of the "spilled" information about A's successful explorations by imitating A's investment. We call this effect the information-spillover effect. Notice that even though A's report by the successful-efforts method is informative, the information spilled may not be complete. For example, when A achieves success in just some of its exploration areas, B does not know which area can bring success. On the other hand, when firm A discloses a successful outcome, A secures its preemptive advantage in the competition, and this advantage may intimidate competitors. We call this effect the preempting effect. In the following analysis, we will illustrate in detail how these two effects interact and affect the equilibrium strategies of both innovator and imitator.

To derive the equilibrium, we proceed by backward induction. At date 3, both firms' exploration outcomes are realized and publicly observed. Solving a standard Cournot game, we have firm $i$ 's

optimal production quantity $q_{i}^{*}=\frac{1+2 a_{i}-a_{j}}{3}$, and firm $i$ 's gross payoff without considering the investment/exploration cost is

$$
\begin{aligned}
& W_{i}\left(a_{i}, a_{j}\right)=q_{i}^{*}\left(1-q_{i}^{*}-q_{j}^{*}+a_{i}\right)=\frac{\left(1+2 a_{i}-a_{j}\right)^{2}}{9}, \\
& \text { with } a_{A}=a \cdot x_{A}, a_{B}= \begin{cases}0 & \text { if } x_{B}=0 \\
a & \text { if } x_{B}=\delta, i, j \in\{A, B\} . \\
\gamma a & \text { if } x_{B}=\sigma\end{cases}
\end{aligned}
$$

Different combinations of the two firms' exploration outcomes give different gross payoffs for the 
two firms. We list these gross payoffs in Table 1 in the Appendix.

\subsubsection{Firm B's Strategies Given Firm A's Report}

We first examine firm B's strategies at date 2, taking firm A's report as given. At date 2, A reports according to its choice of capitalization method that has been determined at date 1 . Notice that under the full-cost regime, A does not disclose its number of successes, therefore $\widehat{x}_{A}=\emptyset$. Firm B observes A's report and makes its own exploration decision $I_{B} \in\{0, s, d\}$ to maximize its expected payoff,

$$
\max _{I_{B}} E\left[\Pi_{B} \mid I_{B}, D\left(I_{A}, \widehat{x}_{A}\right)\right]=E\left[W_{B}\left(a_{B}, a_{A}\right) \mid D\left(I_{A}, \widehat{x}_{A}\right), I_{B}\right]-k_{1}^{B} \cdot t_{B}
$$

Because firm A may report using either the successful-efforts method or the full-cost method, we now analyze B's strategies in these two cases separately. We first study the case in which A uses the successful-efforts method, and then the case in which A reports with the full-cost method.

B's strategies given A's report using the successful-efforts method. If A uses the successfulefforts method to report, firm B observes exactly the number of success(es) A has obtained and knows the value of $a_{A}$, even though $\mathrm{B}$ may not know which area has brought success to A (this happens in the case when $\mathrm{A}$ invests in two areas and reports only one success).

Let's obtain firm B's optimal investment choice for each possible accounting report issued by firm A using the successful-efforts method. To do that, we compare firm B's payoffs across B's investment choices for a given firm A's report, $E\left[\Pi_{B} \mid I_{B}, D\left(I_{A}, \widehat{x}_{A}\right)\right]$. First, it is obvious that when firm A reports no success, exploring a same area as A does not bring any success to B. ${ }^{9}$ Thus firm B explores a different area when A reports zero successes. (The assumption $k_{1}^{B}<\bar{K}$ guarantees that investing in a different area dominates the no-investment strategy.)

\footnotetext{
${ }^{9}$ We list firm B's expected payoffs based on different reports from A by the successful-efforts method, $E\left[\Pi_{B} \mid I_{B}, D\left(I_{A}, \widehat{x}_{A}\right)\right]$, in the Appendix.
} 


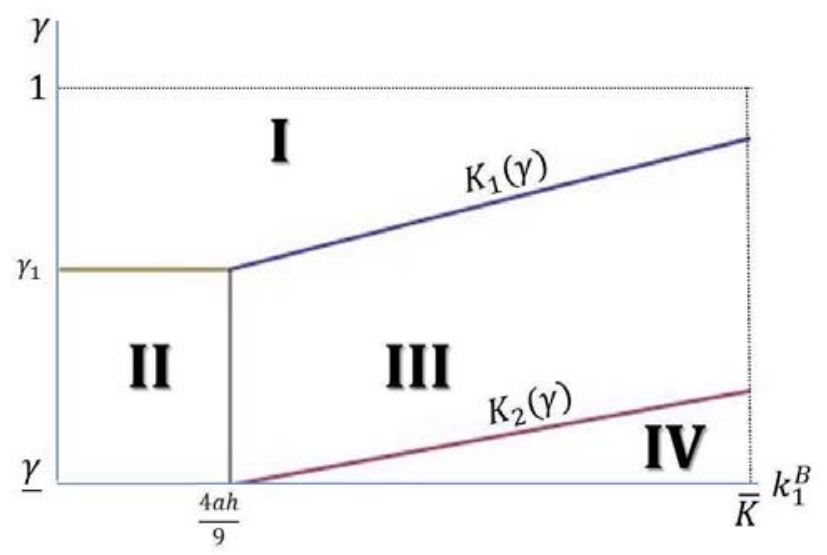

Figure 1: Regions that delimit B's strategies, given that A uses the successful-efforts method.

When firm A reports a non-zero success(es) outcome, firm B's optimal investment strategy depends on both its investment cost $\left(k_{1}^{B}\right)$ and the information-spillover effect. The information spillover, to some extent, can be measured by $\gamma$. Notice that when $\gamma$ is high $(\gamma \rightarrow 1)$, A's disclosed information brings a large benefit to B, as B is able to imitate A's investment and obtain a large increase in its contribution margin. On the other hand, when $\gamma$ is close to zero, B cannot benefit from the information of A's investment outcome. This spillover effect is especially strong when A reports full success in its invested area(s), that is, when either A invests in one area and achieves one success or A invests in two areas and achieves two successes. In the case that A invests in two areas but reports only one success (that is, A reports partial success), the information content is diluted, as B cannot tell which area of A's investments has brought success.

Our analysis shows that B's strategy depends on the relative strength of the spillover and preemptive effects. The relative strength of these effects, in turn, depends on the parameters $\gamma$ and $k_{1}^{B}$. We illustrate B's optimal strategies given A's report by the successful-efforts method in Figure 1.

In Region I in Figure 1, which is delimited by $k_{1}^{B}<\operatorname{Min}\left\{\bar{K}, K_{1}(\gamma)\right\}$ and $\gamma_{1}<\gamma \leq 1$, our 
analysis based on B's expected payoffs shows that $I_{B}^{*}(D)=\sigma$ for $D=(1,1),(2,1)$, or $(2,2) .{ }^{10}$ That is, when the information-spillover effect is significantly strong, firm B will imitate A's investment and explore a same area as firm A, as long as firm A reports any successful exploration.

In Region II, which is delimited by $k_{1}^{B}<\frac{4 a h}{9}$ and $\underline{\gamma}<\gamma \leq \gamma_{1}$, if A reports full success, we still have the result that B invests in a same area as A. However, when A reports partial success, B only has a fifty-percent chance of obtaining success by imitating A, and thus the benefit from imitating A is small (notice that not only $\gamma$ is lower than that in Region I, but also the information content from A's report is diluted when A reports partial success). Therefore, in this case B finds that it is better to invest in a different area when firm A reports partial success.

In Region III, which is delimited by $\operatorname{Max}\left\{\frac{4 a h}{9}, K_{1}(\gamma)\right\}<k_{1}^{B}<\operatorname{Min}\left\{\bar{K}, K_{2}(\gamma)\right\}$, B's cost of investment becomes higher than that in Region II. When A reports full success, we still have the same result as those in Regions I and II that B will invest in a same area. However, now when A reports partial success, B will not invest at all. This is because A only discloses diluted information and has secured some preemptive advantage, while B has only a fifty-percent chance of succeeding by imitating A and has a high cost of investment. Therefore, B will choose not to invest at all.

In Region IV, which is delimited by $K_{2}(\gamma)<k_{1}^{B}<\bar{K}$ and $\gamma>\underline{\gamma}$, we find that B will choose not to invest even if A reports success in both of its areas $\left(I_{B}^{*}(D)=0\right.$ for $\left.D=(2,2)\right)$. It is interesting that even when A reports full success in its two invested areas $(D=(2,2))$ and B can achieve certain success by investing in either of A's areas, B's optimal strategy is not to invest at all. This result is driven by two forces. First, when A has already obtained two successes, its contribution margin per unit has increased by $2 a$, and its competitive advantage is large. That is, A has secured its preemptive advantage in the future competition. Second, as $\gamma$ is small but B's investment cost is high, the benefit of investing cannot outweigh the cost. Overall, even if B

\footnotetext{
${ }^{10}$ The derivations of the closed-form values of all thresholds are available in the Appendix.
} 
obtains perfect information about successful areas from A's report (the information is fully spilled over to B), the preempting effect dominates.

In Region IV when A reports success in its only investment, we find that B invests in the same area, because the information spillover still dominates; however, when A reports partial success, A's secured preemptive advantage as well as B's high investment cost induce B not to invest at all.

Notice that the information-spillover effect as well as the preempting effect exists in all the above different cases and both play roles in B's investment decision. Which effect dominates in the trade-off, together with the consideration of B's investment cost, determines firm B's strategy. Our results of B's optimal strategies given A's successful-efforts reports, denoted by $I_{B}^{*}(D)$, are concluded in Lemma 1.

Lemma 1 Firm B's optimal strategies when firm A reports using the successful-efforts method are summarized in the following table:

\begin{tabular}{|l|l|l|l|l|}
\hline & $D=(1,0)$ or $(2,0)$ & $D=(1,1)$ & $D=(2,1)$ & $D=(2,2)$ \\
\hline Region I & $I_{B}^{*}(D)=d$ & $I_{B}^{*}(D)=s$ & $I_{B}^{*}(D)=s$ & $I_{B}^{*}(D)=s$ \\
\hline Region II & $I_{B}^{*}(D)=d$ & $I_{B}^{*}(D)=s$ & $I_{B}^{*}(D)=d$ & $I_{B}^{*}(D)=s$ \\
\hline Region III & $I_{B}^{*}(D)=d$ & $I_{B}^{*}(D)=s$ & $I_{B}^{*}(D)=0$ & $I_{B}^{*}(D)=s$ \\
\hline Region IV & $I_{B}^{*}(D)=d$ & $I_{B}^{*}(D)=s$ & $I_{B}^{*}(D)=0$ & $I_{B}^{*}(D)=0$ \\
\hline
\end{tabular}

B's strategies given A's report using the full-cost method. Now we consider the case in which A reports using the full-cost method. In this case, B does not know in how many areas A succeeds. Therefore, B has to make the investment decision based on its conjecture of $a_{A}$.

Comparing the expected payoffs of B based on A's report using the full-cost method, $E\left[\Pi_{B} \mid I_{B}, D\left(I_{A}, \emptyset\right)\right]$, we obtain that $E\left[\Pi_{B} \mid d,\left(I_{A}, \emptyset\right)\right]>E\left[\Pi_{B} \mid s,\left(I_{A}, \emptyset\right)\right]$ for $I_{A} \in\{1,2\} .{ }^{11}$ That is, if A reports under the

\footnotetext{
${ }^{11}$ The explicit expressions of firm B's expected payoffs based on firm A's report under the full-cost method, $E\left[\Pi_{B} \mid I_{B}, D\left(I_{A}, \emptyset\right)\right]$, are available in the Appendix.
} 
full-cost regime, exploring a different area from A's area(s) is always a better strategy for B than exploring a same area as A. The intuition is that A provides no information about its exploration outcome under the full-cost regime, and therefore no information "spilled over" to B. B's belief about the probability of success stays unchanged. That is, no matter whether B decides to explore a same area as A or a different area, B's prior belief about the probability of success is $h$. However, if B follows A's exploration and achieves success, B will only get $a_{B}=\gamma a$ and benefit less from the success than from a success in a different area. In addition, with the assumption $k_{1}^{B}<\bar{K}$, for firm $\mathrm{B}$, investing in a different area dominates no investment. Therefore, whenever firm A chooses the full-cost method, firm B will explore a different area. We illustrate this result in Lemma 2.

Lemma 2 When firm A reports using the full-cost method, firm B chooses to invest in a different area.

\subsubsection{Firm A's Reporting-Method Choices}

Now we are back to date 1 to analyze A's decisions on its capitalization method and innovation investments. We denote A's choice of accounting-reporting method to be $R, R \in\{F C, S E\}$, where $F C$ represents the full-cost method and $S E$ represents the successful-efforts method.

We first analyze A's optimal reporting method given A's investment decision incorporating B's optimal responses given in Lemmas 1 and 2. In Section 3.2.3 we will compare A's expected payoffs with different combination of $I_{A}$ and $R$ to derive A's optimal investment strategies and accounting-method choice.

A's reporting-method choices given $I_{A}=1$. We first examine the case in which A invests in one area. Notice that, according to Lemmas 1 and 2, if $\mathrm{A}$ uses the full-cost method, B invests in a different area; if $\mathrm{A}$ uses the successful-efforts method, firm B invests in a same area if $\mathrm{A}$ reports 
success and in a different area otherwise. Therefore, A's expected payoffs with the two alternative reporting methods are as follows:

$$
\begin{gathered}
E\left[\Pi_{A} \mid 1, F C\right]=h\left[h W_{A}(a, a)+(1-h) W_{A}(a, 0)\right]+(1-h)\left[h W_{A}(0, a)+(1-h) W_{A}(0,0)\right]-k_{1}^{A} \\
=\frac{1-[2+a(5-4 h)] a h}{9}-k_{1}^{A} \\
\begin{aligned}
E\left[\Pi_{A} \mid 1, S E\right]= & h W_{A}(a, \gamma a)+(1-h)\left[h W_{A}(0, a)+(1-h) W_{A}(0,0)\right]-k_{1}^{A} \\
& =\frac{1+\{2(1+h-\gamma)+a[5-h-(4-\gamma) \gamma]\} a h}{9}-k_{1}^{A} .
\end{aligned}
\end{gathered}
$$

Our analysis shows that $E\left[\Pi_{A} \mid 1, F C\right]>E\left[\Pi_{A} \mid 1, S E\right]$. That is, A will choose the full-cost method when it invests in one area. Intuitively, when A invests in only one area, the informationspillover effect is very strong because firm B achieves a certain success by imitating A's investment as long as A reports success. Therefore, firm A prefers the full-cost method to avoid revealing any information about its success to prevent B from imitating.

A's reporting method choices given $I_{A}=2$. When $\mathrm{A}$ invests in two areas, according to Lemmas 1 and 2, B's optimal investment strategy depends not only on A's report, but also on the severeness of the information spillover, $\gamma$, and B's cost of investment, $k_{1}^{B}$. To derive A's optimal reporting method, we compare A's expected payoff when choosing the full-cost method, $E\left[\Pi_{A} \mid 2, F C\right]$, with that of choosing the successful-efforts method, $E\left[\Pi_{A} \mid 2, S E\right]$, incorporating firm B's optimal responses in all regions depicted in Figure 1. We illustrate the result in Figure 2, and formally present A's optimal reporting-method choice, $R^{*}$, in Lemma 3.

Lemma 3 In Region FC, A always prefers the full-cost method $\left(R^{*}=F C\right)$; in Region FC/SE, A 


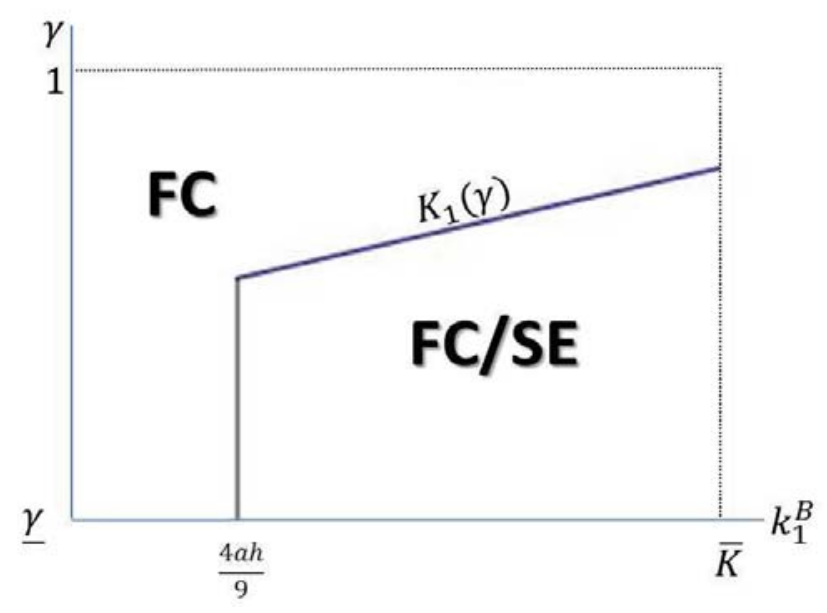

Figure 2: Regions that delimit A's optimal reporting-method choices.

prefers the full-cost method when investing in one area, and prefers the successful-efforts method when investing in two areas $\left(R^{*}=F C\right.$ when $I_{A}=1 ; R^{*}=S E$ when $\left.I_{A}=2\right)$.

In Figure 2, Region FC includes Region I and Region II in Figure 1. That is, $0<k_{1}^{B}<$ $\operatorname{Max}\left\{\frac{4 a h}{9}, K_{1}(\gamma)\right\}$ and $\underline{\gamma}<\gamma<1$. Region FC/SE in Figure 2 is the union of Regions III and IV in Figure 1. That is, Region FC/SE is defined by $\operatorname{Max}\left\{\frac{4 a h}{9}, K_{1}(\gamma)<k_{1}^{B}<\bar{K}\right.$ and $\underline{\gamma}<\gamma<1$.

Notice that in Region $F C, \gamma$ is big or $k_{1}^{B}$ is small. Intuitively, B is likely to imitate A either because the benefit from imitating is large or because the cost of investment is low. Therefore, A chooses the full-cost method to avoid B's imitation. In Region $F C / S E, \gamma$ is relatively small and $k_{1}^{B}$ is relatively large, compared with Region $F C$. B now has a smaller incentive to imitate A due to a high investment cost and a low benefit from imitating, especially when A invests in two areas because the informative content is diluted. Therefore, A chooses the successful-efforts method in Region $F C / S E$ when it invests in two areas to obtain a strong preemptive advantage.

To analyze A's optimal investment decision in different regions, we compare A's investment profits under different combinations of reporting and investment decisions. We find that there is a threshold, $K_{A}\left(\gamma, k_{1}^{B}\right)$, such that A invests in two areas if $k_{2}^{A}<K_{A}\left(\gamma, k_{1}^{B}\right)$, and invests in one area 
otherwise. It is straightforward that firm A invests more when its investment cost is low while it invests less when its cost is high.

\subsubsection{The Equilibrium}

With all the results we have so far, we are now able to derive the equilibrium decisions for both firm A and firm B. The equilibrium strategies are formally presented in Proposition 1 and illustrated in Figure 3.

Proposition 1 (i) For Region FC, firm A chooses to report under the full-cost method and firm $B$ always explores a different area. Firm $A$ explores one area if $k_{2}^{A}>K_{A}\left(\gamma, k_{1}^{B}\right)$ and explores two areas if $k_{2}^{A}<K_{A}\left(\gamma, k_{1}^{B}\right)$.

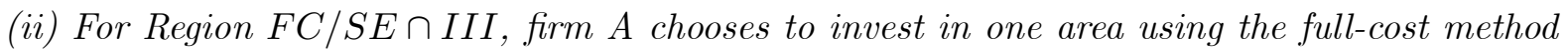
if $k_{2}^{A}>K_{A}\left(\gamma, k_{1}^{B}\right)$, and invests in two areas using the successful-efforts method if $k_{2}^{A}<K_{A}\left(\gamma, k_{1}^{B}\right)$. $B$ invests in a different area if $A$ reports no success or chooses the full-cost method, in a same area if $A$ reports full success, and does not invest at all if $A$ reports partial success.

(iii) For Region $F C / S E \cap I V$, firm $A$ chooses to invest in one area using the full-cost method if $k_{2}^{A}>K_{A}\left(\gamma, k_{1}^{B}\right)$, and invests in two areas using the successful-efforts method if $k_{2}^{A}<K_{A}\left(\gamma, k_{1}^{B}\right)$. $B$ invests in a different area if $A$ reports no success or chooses the full-cost method, in a same area if $A$ reports success in its only investment, and does not invest at all if $A$ reports any success out of two investments.

We illustrate the equilibrium strategies for both firms in Figure 3. First, firm A chooses to use the full-cost method in Region $F C$, where the information-spillover effect is severe ( $\gamma$ is large) or it is cheap for B to invest ( $k_{1}^{B}$ is small). Intuitively, because the information-spillover effect in Region $F C$ is very strong or B's cost of investment is very low, B will imitate A's investment as long as 


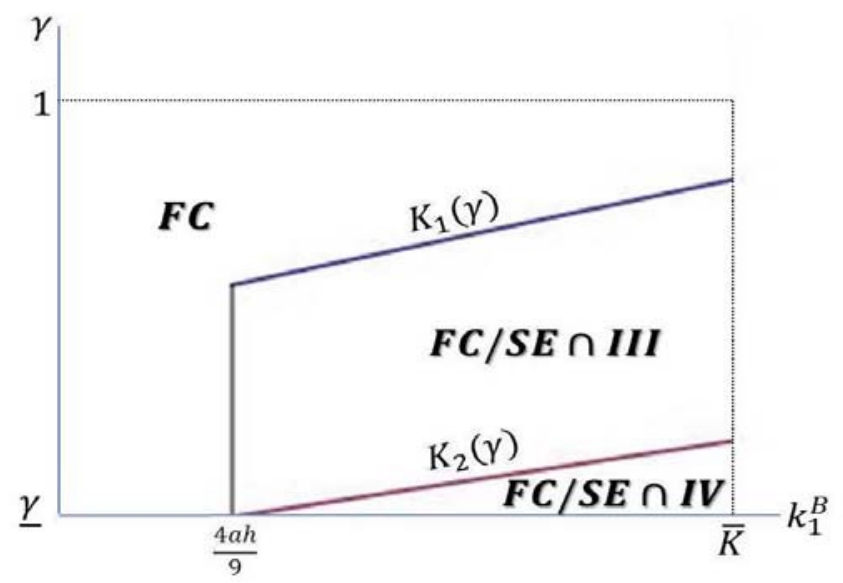

Figure 3: Regions that delimit both firms' optimal strategies.

A reports any success. Therefore, firm A prefers to choose the full-cost method to avoid revealing any information about its success so that it can prevent B from imitating. As a consequence, B will always invest in a different area because it does not obtain any information from A's report.

In Regions $F C / S E \cap I I I$ (the overlapped area of Region $F C / S E$ in Figure 2 and Region $I I I$ in Figure 1) and $F C / S E \cap I V$ (the overlapped area of Region $F C / S E$ in Figure 2 and Region $I V$ in Figure 1), B's cost is relatively high and $\gamma$ is relatively low. Any reported success gives A a competitive advantage as the "Stackelberg leader." When A uses successful-efforts, as $\gamma$ gets smaller, B's benefit from imitating A declines (the information-spillover effect is weakened). In addition, when A's investment cost is low, $\mathrm{A}$ is able to further dilute the information content of its report by investing in two areas, which makes the information-spillover effect even weaker. Now A may have an incentive to choose successful-efforts and disclose its success(es) to intimidate B. B may then choose not to invest at all upon the reported success.

Notice that by using the successful-efforts method, firms communicate two types of information: the probability of success for imitation, and the increase in the contribution margin per unit by the innovator's success(es). When small firms report under the successful-efforts method, the small 
size of their investments makes their accounting reports very informative about the probability of success for potential imitation. Large firms, however, can afford large investments which make their accounting reports much less informative for potential imitators. That is, the information-spillover problem is more severe for small firms. The other information, the information about the increase in the contribution margin per unit (i.e., the increase in competitive advantage), provides firms the preemptive advantage. Firms, especially large firms, are motivated to choose the successful-efforts method to disclose the latter kind of information to intimidate competitors.

The predictions in Propositions 1 are consistent with firms' different choices between the successful-efforts and the full-cost methods in reality. Previous studies have shown that large oil and gas companies usually choose the successful-efforts method, while small oil and gas companies prefer the full-cost method (Sunder, 1976; Deakin, 1979; Dhaliwal, 1980; Bryant, 2003). Conventional wisdom regarding this difference in preferences usually focuses on the consequences on reported earnings. That is, the successful-efforts method may induce more volatile earnings, and small firms cannot afford the market consequences of this volatility. Our analysis provides another explanation from the competition point of view regarding information spillover. That is, small firms with a cost disadvantage are more reluctant to choose the successful-efforts method because they suffer from severe information spillover. Their competitors, especially those with cost and investment advantages, can easily imitate the small firms' exploration and reduce the small firms' competitive advantage from innovation. On the other hand, large firms with cost advantages prefer the successful-efforts method. This is because large firms can afford to make larger investments that dilute the information content of their reported success(es), and they are willing to disclose their success to secure their preemptive advantages. ${ }^{12}$

\footnotetext{
${ }^{12}$ The SEC and FASB also require oil and gas companies to disclose the information of their proved reserves in footnotes. However, this kind of disclosure can hardly substitute for the capitalization of exploration costs under the successul-efforts method.
} 


\section{The Regulatorily-Enforced Accounting Method}

The debate about whether oil and gas companies should retain the option of choosing different accounting methods for their exploration costs has continued for over four decades. In 1977, the SEC proposed FASB 19, which aimed to enforce the successful-efforts method and eliminate the full-cost method. This proposal was rejected by many companies as well as some scholars, and was eventually abandoned by the SEC. Recently, the trend of converging the GAAP with the IFRS has brought this long-standing debate to the spotlight again, as the IFRS does not support the full-cost method.

To shed light on the costs and benefits of eliminating companies' choices between different accounting methods regarding their exploration costs, we examine a setting in which the successfulefforts method is enforced. For completeness of analysis, we also look at a setting in which the full-cost method is the only reporting option. We focus on how the elimination of accountingmethod choices influences firms' investments in exploration/innovation. We find that the enforced successful-efforts method induces either more or less investment in innovation, while the enforced full-cost method always results in less investment in innovation.

First, footnote disclosure of proved reserves is far less timely in revealing firms' successes in exploration activities than the capitalization of exploration cost. An exploratory well should be capitalized on or shortly after the completion of drilling if oil and gas reserves are found, even though the classification of those reserves as proved cannot be made when drilling is completed. The FASB allows firms to determine whether the reserves are proved reserves in one year after the capitalization (FASB Current Text Section Oi5, paragraphs 122-125; SFAS No. 19, paragraphs 31-34), which may result in a large gap in timing between the capitalization of exploration cost and the footnote disclosure of proved reserves.

In addition, the information of proved reserves disclosed in footnotes is not audited, while the capitalization of exploration cost is audited (SFAS No. 69).

Furthermore, the change in proved reserves may not contain the same information content as the capitalization of exploration cost regarding the successes of a firm's exploration. The change may be due to many factors other than the expansion or discovery of new reserves, such as modified estimation of existing wells, changes in technology, and changes in market prices (SFAS No. 69). 


\subsection{The Enforced Successful-Efforts Method}

We first compare firm A's investment decisions under the enforced successful-efforts regime and decisions under the discretionary regime. Since we are more interested in analyzing the impact of accounting regulations on innovative investments as opposed to imitative activities, we focus on firm A's investment decisions.

We derive A's optimal investing strategy under the successful-efforts regime by comparing A's expected payoffs of 1,2 , and 0 investments. We find that there is a threshold for A's cost of the first investment, $K_{1}^{A}$, and a threshold for A's cost of the second investment, $K_{A}^{S E}\left(\gamma, k_{1}^{A}, k_{1}^{B}\right)$ (the values of these thresholds are available in the Appendix), such that when the successful-efforts method is enforced, firm A explores two areas if $k_{2}^{A}<K_{A}^{S E}\left(\gamma, k_{1}^{A}, k_{1}^{B}\right)$, explores one area if $k_{1}^{A}<K_{1}^{A}$ and $k_{2}^{A}>K_{A}^{S E}\left(\gamma, k_{1}^{A}, k_{1}^{B}\right)$, and does not invest at all if $k_{1}^{A}>K_{1}^{A}$ and $k_{2}^{A}>K_{A}^{S E}\left(\gamma, k_{1}^{B}\right)$. We formally present A's optimal investing strategies in Lemma 4. We also illustrate A's investment strategies in Figures 4 and 5.

Lemma 4 If the successful-efforts method is enforced,

(i) when $k_{1}^{A}<K_{1}^{A}$, firm $A$ invests in one area if $k_{2}^{A}>K_{A}^{S E}\left(\gamma, k_{1}^{A}, k_{1}^{B}\right)$, and invests in two areas if $k_{2}^{A}<K_{A}^{S E}\left(\gamma, k_{1}^{A}, k_{1}^{B}\right)$;

(ii) when $k_{1}^{A}>K_{1}^{A}$, firm $A$ does not invest if $k_{2}^{A}>K_{A}^{S E}\left(\gamma, k_{1}^{A}, k_{1}^{B}\right)$, and invests in two areas if $k_{2}^{A}<K_{A}^{S E}\left(\gamma, k_{1}^{A}, k_{1}^{B}\right)$.

Notice that when the successful-efforts method is enforced, A suffers from the information spillover. In particular, when A has a high cost of investments, $k_{1}^{A}>K_{1}^{A}$ and $k_{2}^{A}>K_{A}^{S E}\left(\gamma, k_{1}^{A}, k_{1}^{B}\right)$, it can not afford to increase investment to dilute the information content in its report. Therefore, A chooses not to invest.

Recall that Proposition 1 shows that under the discretionary regime, firm A invests in two 


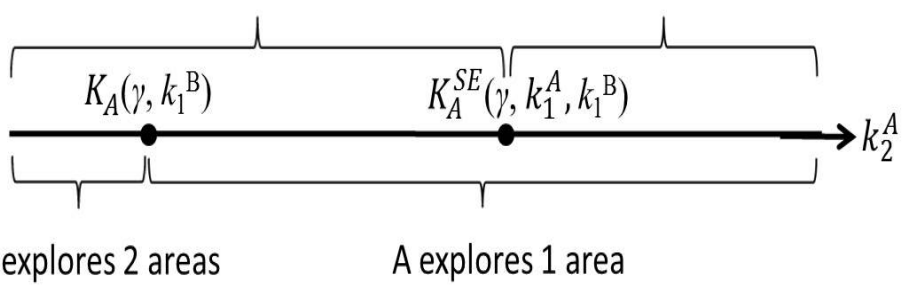

Figure 4: Investment decisions under the enforced successful-efforts regime vs. under the discretionary regime when $k_{1}^{A}<K_{1}^{A}$.

areas with cost $k_{2}^{A}<K_{A}\left(\gamma, k_{1}^{B}\right)$, and invests in one area if $k_{2}^{A}>K_{A}\left(\gamma, k_{1}^{B}\right)$. We now examine the accounting-reporting regime's effect on A's investment strategy by comparing A's investment in Lemma 4 with that in Proposition 1.

Firm A's optimal investment when $k_{1}^{A}<K_{1}^{A}$ is illustrated in Figure 4. When $k_{1}^{A}<K_{1}^{A}$, we can prove that $K_{A}^{S E}\left(\gamma, k_{1}^{A}, k_{1}^{B}\right)>K_{A}\left(\gamma, k_{1}^{B}\right)$. Therefore, when the accounting-reporting regime switches from the discretionary regime to the enforced successful-efforts regime, firm A's investment decision will not change if $k_{2}^{A}<K_{A}\left(\gamma, k_{1}^{B}\right)$ or $k_{2}^{A}>K_{A}^{S E}\left(\gamma, k_{1}^{A}, k_{1}^{B}\right)$. However, if $K_{A}\left(\gamma, k_{1}^{B}\right)<k_{2}^{A}<$ $K_{A}^{S E}\left(\gamma, k_{1}^{A}, k_{1}^{B}\right)$, firm A increases its investment from one area to two areas.

Firm A's optimal investment when $k_{1}^{A}>K_{1}^{A}$ is illustrated in Figure 5 . For $k_{1}^{A}>K_{1}^{A}$, we can prove that $k_{2}^{A}>K_{A}^{S E}\left(\gamma, k_{1}^{A}, k_{1}^{B}\right)$ if $\gamma$ is large or $k_{1}^{B}$ is small (i.e., $\gamma$ and $k_{1}^{B}$ locate in Region $F C$ ). Therefore, firm A does not invest when the successful-efforts regime is enforced. Intuitively, when the information spilled from A's report is highly useful or when B's investment cost is low, B has a strong incentive to imitate A. On the other hand, firm A has high investment costs and can not afford to dilute the informative content in its report by increasing its investment. Thus, A will choose not to invest to avoid the information spillover.

For $k_{1}^{A}>K_{1}^{A}$, we can also prove that $K_{A}^{S E}\left(\gamma, k_{1}^{A}, k_{1}^{B}\right)>K_{A}\left(\gamma, k_{1}^{B}\right)$ if $\gamma$ is small and $k_{1}^{B}$ is large (i.e., $\gamma$ and $k_{1}^{B}$ locate in Region $F C / S E$ ). As depicted in Figure 5 , when the accounting-reporting 


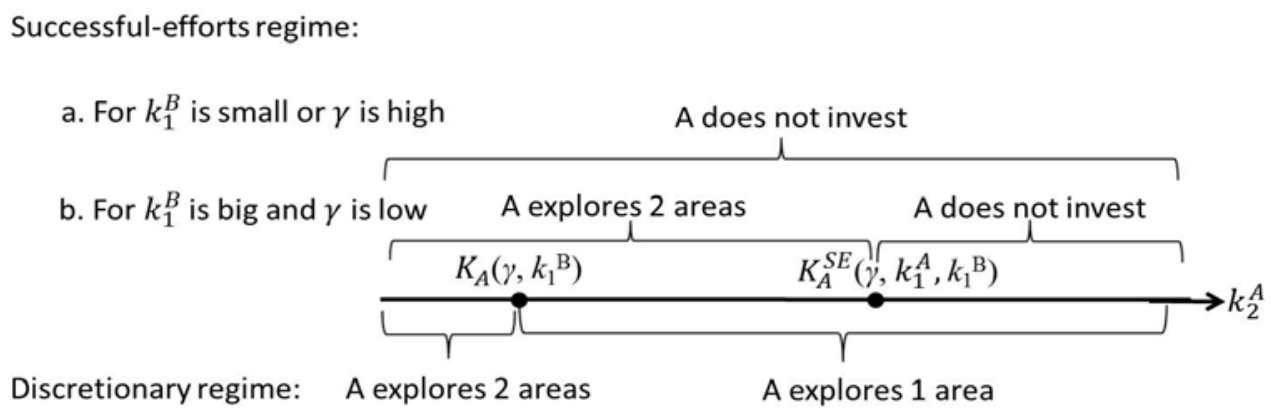

Figure 5: Investment decisions under the enforced successful-efforts regime vs. under the discretionary regime when $k_{1}^{A}>K_{1}^{A}$.

regime switches from the discretionary regime to the successful-efforts regime, firm A's investment decision does not change if $k_{2}^{A}<K_{A}\left(\gamma, k_{1}^{B}\right)$, and decreases from one area to no investment if $k_{2}^{A}>K_{A}^{S E}\left(\gamma, k_{1}^{A}, k_{1}^{B}\right)$. However, A's investment increases from one area to two areas if $K_{A}\left(\gamma, k_{1}^{B}\right)<$ $k_{2}^{A}<K_{A}^{S E}\left(\gamma, k_{1}^{A}, k_{1}^{B}\right)$.

It is surprising that A may increase investment in innovation under the enforced successfulefforts regime. Conventional wisdom may predict a decline in A's investment, because now A does not have the choice of using the full-cost method to prevent information spillover to its competitor. However, our analysis shows that A may increase its investment under the enforced successfulefforts regime, and the reason is directly due to the information-spillover effect. As long as A's cost of investments are not very high, to protect its competitive advantage, A may have to invest more so as to dilute the information content in its report and mitigate the damage from information spilled to its rival. However, if A has very high costs of investment, it cannot afford to increase its investment to dilute the information content and is forced to quit its exploration.

We summarize our results in Proposition 2.

Proposition 2 Compared with the investment in the discretionary regime,

(i) if $k_{2}^{A}<K_{A}\left(\gamma, k_{1}^{B}\right)$, firm A's investing strategy stays unchanged under the enforced successful- 
efforts regime;

(ii) if $K_{A}\left(\gamma, k_{1}^{B}\right)<k_{2}^{A}<K_{A}^{S E}\left(\gamma, k_{1}^{A}, k_{1}^{B}\right)$, firm $A$ invests more under the enforced successfulefforts regime;

(iii) if $k_{2}^{A}>K_{A}^{S E}\left(\gamma, k_{1}^{A}, k_{1}^{B}\right)$, firm $A$ invests less under the enforced successful-efforts when $k_{1}^{A}>K_{1}^{A}$, and invests at the same amount when $k_{1}^{A}<K_{1}^{A}$.

\subsection{The Enforced Full-Cost Method}

Although regulators have no intention of imposing the full-cost method (in fact, regulators always try to eliminate the full-cost choice), for the completeness of the analysis, we also examine a case in which firms can only use the full-cost method to recognize their exploration costs. ${ }^{13}$ We think it may still provide us insight on regulatory implications. To derive A's optimal investment strategies under the full-cost regime, we need to compare A's expected payoffs $E\left[\Pi_{A} \mid I_{A}, F C\right]$ with $I_{A} \in\{1,2\}$, incorporating firm B's optimal responses in Lemma 2. We find that there is a threshold of A's investment cost, $K_{A}^{F C}$, such that firm A invests in two areas with a cost $k_{2}^{A}<K_{A}^{F C}$ and invests in only one area if $k_{2}^{A}>K_{A}^{F C}$. We can prove that $K_{A}\left(\gamma, k_{1}^{B}\right) \geq K_{A}^{F C}$ for any $\gamma$ and $k_{1}^{B}$. As shown in Figure 6, when switching the accounting-reporting regime from the discretionary regime to the full-cost regime, firm A's investment does not change if $k_{2}^{A}>K_{A}\left(\gamma, k_{1}^{B}\right)$ or $k_{2}^{A}<K_{A}^{F C}$. However, when $K_{A}\left(\gamma, k_{1}^{B}\right)>k_{2}^{A}>K_{A}^{F C}$, firm A will reduce its investment from two areas to one area. We formally state the result in Proposition 3.

Proposition 3 Compared with the investment in the discretionary regime, firm A invests less in innovation under the enforced full-cost regime.

\footnotetext{
${ }^{13}$ In practice, because a firm can still preempt rivals by revealing favorable information through other channels-such as disclosures in footnotes of the financial reports or disclosures through media-the enforced full-cost method may not eliminate the preempting effect. Nevertheless, we still examine this hypothetical setting for the completeness of the analysis.
} 


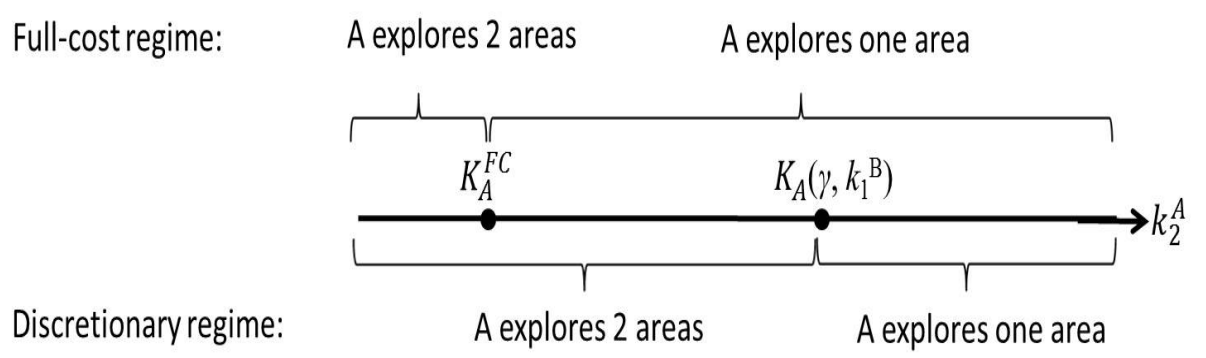

Figure 6: Firms' investment decisions under the enforced full-cost regime vs. under the discretionary regime.

It may also seem counter-intuitive that A would invest less under the enforced full-cost regime.

With the full-cost method, firm $\mathrm{A}$ is not concerned about the damage from information spillover to its competitor. However, it also loses its capability to preempt its rival by reporting its success using the successful-efforts method. That is, although there is no information spillover, the benefit from the preempting effect disappears as well. Thus, A is more reluctant to invest in innovation and its optimal investment declines.

\section{Alternative Setup}

In the main setting of our paper, we examine the innovator-imitator game assuming that $\mathrm{A}$ is a big firm with a lower overall investment cost while B is a small firm. In this section, we will consider the reverse case in which $\mathrm{A}$ is a small firm and $\mathrm{B}$ is a big firm. ${ }^{14}$ Now we assume $\mathrm{A}$ can only invest in up to one area while B can invest in up to two areas. That is, we assume A's cost of investing in one area is $k_{1}^{A}>0$, and the cost of investing in a second area, $k_{2}^{A}$, is $\infty$. B's

\footnotetext{
${ }^{14}$ In our paper, we are interested in cases of competition between firms with different sizes, as in reality the resistance to the proposal of emilinating the full-cost method is always from firms of smaller size.

Although settings in which firms are of similar sizes are not our focus, we examined the cases that both innovator and imitator are of the same size for completeness. In the setting in which both firms are small, it is easy to verify that the firms' accounting-method choices depend on their investment costs and their decisions are determined by information spillover and preempting effects, which we have identified in the main setting. In the setting in which both firms are large, we have countless cases and the analysis is hardly presentable. Nevertheless, the firms' accounting-method choices are still driven by the same two effects.
} 
investment cost in the first area is $k_{1}^{B}>0$. B's cost for the second investment is $k_{2}^{B}>0$, and we assume $k_{2}^{B}<\overline{K_{2}^{B}}=\frac{4 a h(1+a+a h)}{9}$ so that firm B will optimally invest in two areas when firm A reports under the full-cost method. Otherwise, if $k_{2}^{B}$ is too high, A is able to preempt B simply by choosing the full-cost method and does not have any incentive to choose the successful-efforts method. In addition, as in the main setting, we assume $k_{1}^{A}, k_{1}^{B}<\bar{K}$.

The payoff functions of firms A and B in this alternative setup are, respectively:

$$
\begin{gathered}
\Pi_{A}=q_{A}\left(1-q_{A}-q_{B}+a_{A}\right)-k_{1}^{A} \cdot t_{A}^{\prime}, \\
\Pi_{B}=q_{B}\left(1-q_{A}-q_{B}+a_{B}\right)-k_{1}^{B}-k_{2}^{B} \cdot t_{B}^{\prime},
\end{gathered}
$$

where $t_{A}^{\prime}$ is an indicator variable that equals one if $\mathrm{A}$ explores one area and equals zero if $\mathrm{A}$ does not not invest; $t_{B}^{\prime}$ is an indicator variable that is one if B invests in two areas and equals to zero if $\mathrm{B}$ invests in one area.

We first consider the case in which A uses the successful-efforts method in this alternative setup. We find that if A reports a success, B will imitate A's investment. In addition, when $k_{2}^{B}$ is sufficiently low, B will also invest in an additional area. If A reports no success, B will invest in two different areas. The equilibrium in this alternative setup when A uses the successful-efforts is stated in Lemma 5.

Lemma 5 In the alternative setup, when A uses the successful-efforts method,

(i) if firm A reports failure or does not invest at all, firm B will invest in two different areas;

(ii) if firm A reports a success, firm B invests in the same area, and invests in one more different area if $k_{2}^{B}<\frac{4 a h(1+2 a \gamma)}{9}$.

We then consider the case in which A uses the full-cost method. We find that as B obtains no 
information from A's report, B will invest in two different areas. This result is formally stated in Lemma 6 .

Lemma 6 In the alternative setup, when A uses the full-cost method, firm B will invest in two different areas.

Following a similar analysis to that in the main setup, we derive the equilibrium of A and B's optimal investment strategy and A's optimal reporting strategy. We formally present the results in Proposition 4.

Proposition 4 For $\widehat{\gamma_{1}}<\gamma \leq 1$, or $\underline{\gamma}<\gamma \leq \widehat{\gamma_{1}}$ and $k_{2}^{B}<\frac{4 a h(1+2 a \gamma)}{9}$, firm A invests in one area and chooses to report using the full-cost regime. Firm B invests in two different areas.

For $\underline{\gamma}<\gamma \leq \widehat{\gamma_{1}}$ and $K_{2}^{B}>k_{2}^{B}>\frac{4 a h(1+2 a \gamma)}{9}$, firm $A$ invests in one area and chooses to report using the successful-effort regime. Firm B invests in a same area if A reports success and invests in two different areas otherwise.

$$
\widehat{\gamma_{1}}=\frac{2 a-\sqrt{1+2 a[2+a(2-h)](1-h)}+1}{a} .
$$

The intuition here is similar to that in the main setting. The innovator's and imitator's strategies are decided by the interaction between the information-spillover effect and the preempting effect. When the information-spillover effect is strong, or firm B's investment cost is low, B has a stronger incentive to imitate A's successful investment. Therefore, A will choose the full-cost method to avoid B's imitation. When the information-spillover effect becomes weaker, A may have incentive to choose the successful-efforts method to preempt B's investment through disclosing its success. Specifically, as B's investment cost becomes higher, although it may still imitate A's successful investment, B will invest in only one area when A reports success; while if A chooses the full-cost method, B does not have any information about A's success and will invest in two different areas. 


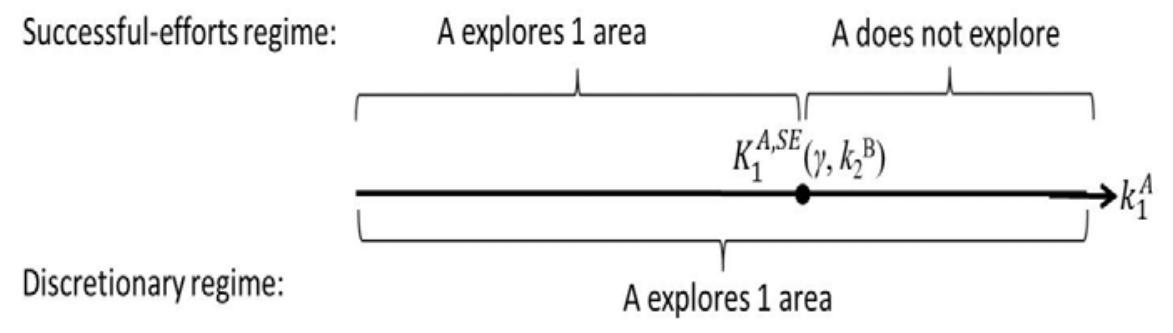

Figure 7: Firms' investment decisions under the enforced successful-efforts regime vs. under the discretionary regime in the alternative setup.

For A, it is actually better to chooses the successful-efforts since A's report of any success secures its preemptive advantage.

We then examine the cases of enforced accounting methods in this alternative setup. We find that when the successful-efforts method is enforced, there is a threshold $K_{1}^{A, S E}\left(\gamma, k_{2}^{B}\right)$ such that firm A will invest if $k_{1}^{A}<K_{1}^{A, S E}\left(\gamma, k_{2}^{B}\right)$ and will not invest if $k_{1}^{A}>K_{1}^{A, S E}\left(\gamma, k_{2}^{B}\right) .{ }^{15}$ The investment decisions of firm A with the enforced successful-efforts method, compared with those in the discretionary-method regime, are illustrated in Figure 7. As depicted in Figure 7, when the accounting-reporting method is changed from the discretionary regime to the enforced successfulefforts regime, firm A with $k_{1}^{A} \in\left(K_{1}^{A, S E}\left(\gamma, k_{2}^{B}\right), \bar{K}\right)$ will stop investing. The intuition is that as A is a small firm with very high investment costs, A cannot afford an additional investment to dilute the informative content in its accounting report under the successful-efforts regime. Firm A will stop investing because its successful investment will always be imitated by its competitor. We conclude this finding in Proposition 5.

Proposition 5 In the alternative setup, compared with the investment in the discretionary regime, firm A invests less in innovation under the enforced successful-efforts regime.

\footnotetext{
${ }^{15} K_{1}^{A, S E}\left(\gamma, k_{2}^{B}\right)$ 's value is available in the Appendix.
} 
We also examine firm A's innovative-investment decision in this alternative setup under the enforced full-cost regime. We find that firm A will still invest if the full-cost method is enforced. Therefore, the enforcement of the full-cost method does not affect A's investment decision. We conclude this finding in Proposition 6.

Proposition 6 In the alternative setup, firm A's investment in the full-cost regime is the same as that in the discretionary regime.

\section{Empirical Implications}

Our study provides empirical implications that are either consistent with the extant empirical evidence, or that may be tested by future empirical research. First, our model shows that small firms (i.e., firms with higher investment costs and smaller investments size) are concerned mainly about the information spillover of their accounting disclosures and, as a result, tend to choose the full-cost method. Large firms (firms with lower investment costs and larger investments), however, place more weight on the preempting effect of their accounting disclosures and, consequently, prefer the successful-efforts method. These predictions are consistent with firms' choices between successful-efforts and full-cost methods in reality. It is well documented that large oil and gas companies usually choose successful-efforts, while small oil and gas companies prefer the full-cost method (Sunder, 1976; Deakin, 1979; Dhaliwal, 1980; Bryant, 2003). Extant empirical studies have examined the determinants of different accounting-disclosure choices in the oil and gas industry, but to our knowledge there is no direct empirical test of whether market competitive forces have implications on firms' choices over different disclosure methods.

Second, our model also sheds light on the consequences of enforcing uniformity in the accounting treatment of exploratory investments. For instance, conventional wisdom may suggest that enforc- 
ing the successful-efforts method might induce small firms to reduce their exploratory investments to mitigate the subsequent earnings volatility. However, our model indicates that competitive concerns may actually induce small firms to increase their investments. Indeed, if the successful-efforts method is enforced, those firms with a serious concern for a potential information spillover may respond by undertaking larger investments to dilute the information content of their accounting disclosures. Nevertheless, our model also predicts that those small firms that are not be able to afford larger investments may instead reduce them. Indeed, facing a smaller expected return on their investments due to a larger information spillover, they are left only with the option to reduce their investments in exploration. The extant empirical evidence on the potential effects of enforcing the successful-efforts method is very scarce. Deakin (1979) analyzes the data of oil and gas companies around the proposal of SFAS 19, which aimed to eliminate the full-cost method, and finds that the full-cost firms responded with more aggressive investments in exploration than the firms that used the successful-efforts method (although the difference is not significant). This very limited evidence seems to point in the direction of our prediction that some small firms may increase their investments in exploration to dilute the information-spillover effect when the successful-efforts method is enforced (Proposition 2). The lack of significance may be due to the test's inability to distinguish between firms that are able to afford larger investments and firms that are not able to do so. More powerful tests may actually test the predictions of our model more accurately.

Our study provides also a potential explanation for several additional puzzling empirical findings. Dyckman and Smith (1978) examine the movement of successful-efforts and full-cost firms' stock returns around the FASB's release of the Exposure Draft (ED) in 1977, which proposed the enforcement of the successful-efforts method. They find a decline in stock prices for both full-cost firms and successful-efforts firms in response to the issuance of the ED. This is contrary to the conventional belief that successful-efforts firms should not have been affected by the mandated 
change in the accounting method because the new regulation implied no change in their reporting. According to our study, small innovators who choose the full-cost method under the discretionary regime may increase their investments when the successful-efforts method is enforced. This, in turn, may result in a more competitive product market in which all firms obtain a lower profit. This prediction provides a potential explanation for the empirical finding that both full-cost and successful-efforts firms' stock prices declined in response to the ED. An analogous reasoning can potentially explain another empirical finding by Dyckman and Smith. Dyckman and Smith show that successful-efforts firms that invested more on exploration suffered a larger decline in their stock price than successful-efforts firms with smaller exploration investments. From our previous argument that enforcing the successful-efforts method would yield a more competitive environment, one can infer that the return of exploration investments should decline accordingly. Therefore, the successful-efforts firms with larger exploratory investments should be more negatively affected. Finally, Dyckman and Smith find that, contrary to the case of the successful-efforts firms, the decline in average returns for the full-cost firms that invest less in explorative activities is larger than those for the full-cost firms that invest more in exploration. This finding may also be consistent with the prediction of our study. Our model implies that firms that invest more in exploration are less affected by the information-spillover effect than firms that invest less in exploration. Therefore full-cost firms with more exploration investments will suffer less when the regulator enforces the successful-efforts method. In other words, firms with less exploration investments are forced to distort more their investment decisions to avoid information spillover.

\section{Conclusions}

In this study, we examine firms' investments in explorative initiatives and their choices of capitalization method in a product-market competition setting. Because the capitalization of exploration 
expenditures may contain information about whether a firm's exploration investment is successful, financial reports may reveal important information to competitors, and thus may have real consequences in product-market competition. In our paper, we identify two driving forces that induce firms to choose different capitalization methods: an information-spillover effect and a preempting effect. We also find that enforcing an accounting method that requires firms to capitalize expenditures of successful explorations may increase or decrease innovation investment. Our study sheds light on the impact that the accounting capitalization of exploratory costs has on firms' exploration investments.

\section{References}

[1] Arya, A., H. Frimor and B. Mittendorf. "Discretionary Disclosure of Proprietary Information in a Multi-Segment Firm." Management Science 56, No. 4 (2010): 645-658.

[2] Arya, A. and B. Mittendorf. "The Interaction among Disclosure, Competition between Firms, and Analyst Following." Journal of Accounting and Economics 43 (2007): 321-339.

[3] Bagnoli, M. and S. G. Watts. "Oligopoly, Disclosure and Earnings Management." The Accounting Review 85, No. 4 (2010): 1191-1214.

[4] Bandyopadhyay, S. P. "Market Reaction to Earnings Announcements of Successful Efforts and Full Cost Firms in the Oil and Gas Industry." The Accounting Review 69 (1994), No. 4: $657-674$.

[5] Bryant, L. "Relative Value Relevance of the Successful Efforts and Full Cost Accounting Methods in the Oil and Gas Industry." Review of Accounting Studies 8 (2003), No. 1: 5-28.

[6] Collins, D. W., and W. T. Dent. "The Proposed Elimination of Full Cost Accounting in the Extractive Petroleum Industry: An Empirical Assessment of the Market Consequences.” 
Journal of Accounting and Economics 1(1979): 3-44.

[7] Darrough, M. N. and N M. Stoughton. "Financial Disclosure Policy in an Entry Game." Journal of Accounting and Economics 12 (1990): 219-243.

[8] Deakin, E. B. "An Analysis of Differences between Non-Major Oil Firms Using Successful Efforts and Full Cost Methods." The Accounting Review 54 (1979), No. 4: 722-734.

[9] Dhaliwal, D. S. "The Effect of the Firm's Capital Structure on the Choice of Accounting Methods." The Accounting Review 55 (1980), No. 1: 78-84.

[10] Dyckman, T. R. and A. J. Smith. "Financial accounting and reporting by oil and gas producing companies. A study of information effects." Journal of Accounting and Economics 1 (1978): 45-75.

[11] Feltham, G. A., and J. Z. Xie. "Voluntary Financial Disclosure in an Entry Game with Continua of Types." Contemporary Accounting Research 9 (1992), Issue 1: 46-80.

[12] Harris, T. S., and J. A. Ohlson. "Accounting Disclosures and the Market's Valuation of Oil and Gas Properties." The Accounting Review 62 (1987), No. 4: 651-670.

[13] Johnson, W. B., and R. Ramanan. "Discretionary Accounting Changes from 'Successful Efforts' to 'Full Cost' Methods: 1970-76." The Accounting Review 63 (1988), No. 1: 96-110.

[14] Jung, W., and Y. Kwon. "Disclosure when the Market is Unsure of Information Endowment of Managers." Journal of Accounting Research 26 (1988): 146-153.

[15] Lilien, S., and V. Pastena. "Determinants of Intra-method Choice in the Oil and Gas Industry." Journal of Accounting and Economics 4 (1982), Issue 3: 145-170.

[16] Pae, S. "Selective Disclosures in the Presence of Uncertainty about Information Endowment." Journal of Accounting and Economics 39 (2005): 383-409. 
[17] Sunder, S. "Properties of Accounting Numbers under Full Costing and Successful-Efforts Costing in the Petroleum Industry." The Accounting Review 51 (1976), No. 1: 1-18.

\section{Appendix I}

We first list firm A and B's gross payoffs given different combinations of the two firms' exploration outcomes, $W_{A}$ and $W_{B}$ in Table $1 . W_{A}$ and $W_{B}$ are useful in later proofs.

\begin{tabular}{|l|l|l|l|}
\hline & $x_{B}=0$ & $x_{B}=\delta$ & $x_{B}=\sigma$ \\
\hline$x_{A}=0$ & $\frac{1}{9}, \frac{1}{9}$ & $\frac{(1-a)^{2}}{9}, \frac{(1+2 a)^{2}}{9}$ & - \\
\hline$x_{A}=1$ & $\frac{(1+2 a)^{2}}{9}, \frac{(1-a)^{2}}{9}$ & $\frac{(1+a)^{2}}{9}, \frac{(1+a)^{2}}{9}$ & $\frac{(1+2 a-\gamma a)^{2}}{9}, \frac{(1-a+2 \gamma a)^{2}}{9}$ \\
\hline$x_{A}=2$ & $\frac{(1+4 a)^{2}}{9}, \frac{(1-2 a)^{2}}{9}$ & $\frac{(1+3 a)^{2}}{9}, \frac{1}{9}$ & $\frac{(1+4 a-\gamma a)^{2}}{9}, \frac{(1-2 a+2 \gamma a)^{2}}{9}$ \\
\hline
\end{tabular}

Table 1: Firms A and B's profits, $W_{A}, W_{B}$ given the outcomes of explorations

For example, in the case that $\mathrm{A}$ and $\mathrm{B}$ both obtain a successful exploration in the same area, firm A's contribution margin per unit is increased by $a$, and firm B's contribution margin per unit is increased by $\gamma a$. Firm A then chooses its production quantity $q_{A}$ to maximize its profit $q_{A}\left(1-q_{B}-q_{A}+a\right)$, and firm B chooses production quantity $q_{B}$ to maximize its profit $q_{B}\left(1-q_{A}-\right.$ $\left.q_{B}+\gamma a\right)$. In the equilibrium, $q_{A}^{*}=\frac{1+(2-\gamma) a}{3}$ and $q_{B}^{*}=\frac{1+(2 \gamma-1) a}{3}$. Firm A and firm B's gross payoffs without considering the exploration cost are $W_{A}(a, \gamma a)=\frac{(1+2 a-\gamma a)^{2}}{9}$ and $W_{B}(\gamma a, a)=\frac{(1-a+2 \gamma a)^{2}}{9}$, respectively.

Second, we present the close-form expressions of firm B's expected payoffs based on A's reports, $E\left[\Pi_{B} \mid I_{B}, D\left(I_{A}, \widehat{x}_{A}\right)\right]$, which will be used in later proofs.

When A reports under the successful-efforts method, given A's report $D=\left(I_{A}, \widehat{x}_{A}\right)$ and B's investment decision $I_{B}$, firm B's expected payoffs are: 


$$
\begin{aligned}
& E\left[\Pi_{B} \mid 0, D(1,0)\right]=E\left[\Pi_{B} \mid 0, D(2,0)\right]=W_{B}(0,0)=\frac{1}{9}, \\
& E\left[\Pi_{B} \mid s, D(1,0)\right]=E\left[\Pi_{B} \mid s, D(2,0)\right]=W_{B}(0,0)-k_{1}^{B}=\frac{1}{9}-k_{1}^{B}, \\
& E\left[\Pi_{B} \mid d, D(1,0)\right]=E\left[\Pi_{B} \mid d, D(2,0)\right]=h W_{B}(a, 0)+(1-h) W_{B}(0,0)-k_{1}^{B}=\frac{1+4 a h(1+a)}{9}-k_{1}^{B}, \\
& E\left[\Pi_{B} \mid 0, D(1,1)\right]=W_{B}(0, a)=\frac{(1-a)^{2}}{9}, \\
& E\left[\Pi_{B} \mid s, D(1,1)\right]=W_{B}(\gamma a, a)-k_{1}^{B}=\frac{(1-a+2 a \gamma)^{2}}{9}-k_{1}^{B}, \\
& E\left[\Pi_{B} \mid d, D(1,1)\right]=h W_{B}(a, a)+(1-h) W_{B}(0, a)-k_{1}^{B}=\frac{(1-a)^{2}+4 a h}{9}-k_{1}^{B}, \\
& E\left[\Pi_{B} \mid 0, D(2,1)\right]=W_{B}(0, a)=\frac{(1-a)^{2}}{9}, \\
& E\left[\Pi_{B} \mid s, D(2,1)\right]=\frac{1}{2} W_{B}(\gamma a, a)+\frac{1}{2} W_{B}(0, a)-k_{1}^{B}=\frac{1-2 a(1-\gamma)+a^{2}[1-2(1-\gamma) \gamma]}{9}-k_{1}^{B}, \\
& E\left[\Pi_{B} \mid d, D(2,1)\right]=h W_{B}(a, a)+(1-h) W_{B}(0, a)-k_{1}^{B}=\frac{(1-a)^{2}+4 a h}{9}-k_{1}^{B}, \\
& E\left[\Pi_{B} \mid 0, D(2,2)\right]=W_{B}(0,2 a)=\frac{(1-2 a)^{2}}{9}, \\
& E\left[\Pi_{B} \mid s, D(2,2)\right]=W_{B}(\gamma a, 2 a)-k_{1}^{B}=\frac{(1-2 a+2 a \gamma)^{2}}{9}-k_{1}^{B}, \\
& E\left[\Pi_{B} \mid d, D(2,2)\right]=h W_{B}(a, 2 a)+(1-h) W_{B}(0,2 a)-k_{1}^{B}=\frac{1+4 a(a+h-a h-1)}{9}-k_{1}^{B} .
\end{aligned}
$$

When A reports under the full-cost method, given A's report $D=\left(I_{A}, \emptyset\right)$ and B's investment decision $I_{B}$, firm B's expected payoffs are: 


$$
\begin{aligned}
E\left[\Pi_{B} \mid 0, D(1, \emptyset)\right] & =h W_{B}(0, a)+(1-h) W_{B}(0,0)=\frac{1-(2-a) a h}{9}, \\
E\left[\Pi_{B} \mid s, D(1, \emptyset)\right] & =h W_{B}(\gamma a, a)+(1-h) W_{B}(0,0)-k_{1}^{B}=\frac{1-h-h(1-a+2 a \gamma)^{2}}{9}-k_{1}^{B}, \\
E\left[\Pi_{B} \mid d, D(1, \emptyset)\right] & =(1-h) E\left[\Pi_{B} \mid d, D(1,0)\right]+h E\left[\Pi_{B} \mid d, D(1,1)\right]=\frac{1+2 a h+a^{2} h(5-4 h)}{9}-k_{1}^{B}, \\
E\left[\Pi_{B} \mid 0, D(2, \emptyset)\right] & =h^{2} W_{B}(0,2 a)+(1-h)^{2} W_{B}(0,0)+2 h(1-h) W_{B}(0, a)=\frac{1+2 a h[2+a-(4-a) h]}{9}, \\
E\left[\Pi_{B} \mid s, D(2, \emptyset)\right] & =h^{2} E\left[\Pi_{B} \mid s, D(2,2)\right]+(1-h)^{2} E\left[\Pi_{B} \mid s, D(2,0)\right]+2 h(1-h) E\left[\Pi_{B} \mid s, D(2,1)\right] \\
& =\frac{1+2 a h[2(\gamma-1)(1+a \gamma)+a(1+h-2 h \gamma)]}{9}-k_{1}^{B}, \\
E\left[\Pi_{B} \mid d, D(2, \emptyset)\right] & =h^{2} E\left[\Pi_{B} \mid d, D(2,2)\right]+(1-h)^{2} E\left[\Pi_{B} \mid d, D(2,0)\right]+2 h(1-h) E\left[\Pi_{B} \mid d, D(2,1)\right] \\
& =\frac{1+6 a^{2}(1-h) h}{9}-k_{1}^{B},
\end{aligned}
$$

\section{Proof of Lemma 1}

Proof. 1. When firm A reports full failure in its exploration, because

$$
\begin{aligned}
E\left[\Pi_{B} \mid s, D\left(I_{A}, 0\right)\right]-E\left[\Pi_{B} \mid d, D\left(I_{A}, 0\right)\right] & =\frac{-4 a(1+a) h}{9}<0, \\
\text { and } E\left[\Pi_{B} \mid 0, D\left(I_{A}, 0\right)\right]-E\left[\Pi_{B} \mid d, D\left(I_{A}, 0\right)\right] & =k_{1}^{B}-\frac{4 a(1+a) h}{9}<0 \text { for } k_{1}^{B}<\bar{K},
\end{aligned}
$$

firm B's optimal decision is $d$, namely $I_{B}^{*}(D)=d$ for $D=\left(I_{A}, 0\right)$. 
2. When firm A reports at least one successful exploration, we first compare firm B's expected payoff with strategy $s$ and that with strategy $d$, and obtain the following results:

$$
\begin{aligned}
E\left[\Pi_{B} \mid s, D(2,1)\right]-E\left[\Pi_{B} \mid d, D(2,1)\right] & =\frac{2 a\{[1-(1-\gamma) a] \gamma-2 h\}}{9}, \\
E\left[\Pi_{B} \mid s, D(2,2)\right]-E\left[\Pi_{B} \mid d, D(2,2)\right] & =\frac{4 a[\gamma-(1-a) h-(2-\gamma) a \gamma]}{9}, \\
E\left[\Pi_{B} \mid s, D(1,1)\right]-E\left[\Pi_{B} \mid d, D(1,1)\right] & =\frac{4 a\{[1-(1-\gamma) a] \gamma-h\}}{9} .
\end{aligned}
$$

We can prove that

$$
\begin{aligned}
& E\left[\Pi_{B} \mid s, D(2,1)\right]-E\left[\Pi_{B} \mid d, D(2,1)\right]>0 \text { iff } \gamma>\frac{a+\sqrt{(a-1)^{2}+8 a h}-1}{2 a}, \\
& E\left[\Pi_{B} \mid s, D(2,2)\right]-E\left[\Pi_{B} \mid d, D(2,2)\right]>0 \text { iff } \gamma>\frac{\sqrt{1+4 a(a-1)(1-h)}-1}{2 a}+1 \\
& E\left[\Pi_{B} \mid s, D(1,1)\right]-E\left[\Pi_{B} \mid d, D(1,1)\right]>0 \text { iff } \gamma>\frac{a+\sqrt{(a-1)^{2}+4 a h}-1}{2 a} .
\end{aligned}
$$

We set $\gamma_{1}=\frac{a+\sqrt{(a-1)^{2}+8 a h}-1}{2 a}, \gamma_{2}=\frac{\sqrt{1+4 a(a-1)(1-h)}-1}{2 a}+1, \gamma_{3}=\frac{a+\sqrt{(a-1)^{2}+4 a h}-1}{2 a}$, and we can prove that $\gamma_{3}<\gamma_{2}<\gamma_{1}$.

In the next step, we solve B's optimal investment strategy based on $\gamma$.

(i) When $\gamma_{1}<\gamma \leq 1$ :

From the above results, we have $E\left[\Pi_{B} \mid s, D\right]>E\left[\Pi_{B} \mid d, D\right]$ for $D=(1,1),(2,1)$, or $(2,2)$. Therefore, $s$ is a dominating strategy to $d$ for firm B. We then compare firm B's expected payoff by strategy $s$ with that by strategy 0 , and obtain the following results:

$$
\begin{aligned}
& E\left[\Pi_{B} \mid s, D(2,1)\right]-E\left[\Pi_{B} \mid 0, D(2,1)\right]=\frac{2 a \gamma[1-(1-\gamma) a]}{9}-k_{1}^{B}>0 \text { iff } k_{1}^{B}<\frac{2 a \gamma[1-(1-\gamma) a]}{9}, \\
& E\left[\Pi_{B} \mid s, D(2,2)\right]-E\left[\Pi_{B} \mid 0, D(2,2)\right]=\frac{4 a \gamma\{1-(2-\gamma) a]}{9}-k_{1}^{B}>0 \text { for any } k_{1}^{B}<\bar{K}, \\
& E\left[\Pi_{B} \mid s, D(1,1)\right]-E\left[\Pi_{B} \mid 0, D(1,1)\right]=\frac{4 a \gamma\{1-(1-\gamma) a]}{9}-k_{1}^{B}>0 \text { for any } k_{1}^{B}<\bar{K} .
\end{aligned}
$$


We set $K_{1}(\gamma)=\frac{2 a \gamma[1-(1-\gamma) a]}{9}$. From the above results we obtain that $I_{B}^{*}(D)=s$ for $D=(1,1)$ or $(2,2) ; I_{B}^{*}(D)=s$ for $D=(2,1)$ if $k_{1}^{B}<\operatorname{Min}\left\{\bar{K}, K_{1}(\gamma)\right\}$ which is Region I, and $I_{B}^{*}(D)=0$ for $D=(2,1)$ if $K_{1}(\gamma)<k_{1}^{B}<\bar{K}$, which is part of Region III.

(ii) When $\gamma_{2}<\gamma \leq \gamma_{1}$ :

we can prove that

$E\left[\Pi_{B} \mid d, D(2,1)\right]>E\left[\Pi_{B} \mid s, D(2,1)\right]$, and $E\left[\Pi_{B} \mid d, D(2,1)\right]>E\left[\Pi_{B} \mid 0, D(2,1)\right]$ iff $k_{1}^{B}<\frac{4 a h}{9} ;$

$E\left[\Pi_{B} \mid s, D(2,2)\right]>E\left[\Pi_{B} \mid d, D(2,2)\right]$, and $E\left[\Pi_{B} \mid s, D(2,2)\right]>E\left[\Pi_{B} \mid 0, D(2,2)\right]$ iff $k_{1}^{B}<\frac{4 a \gamma[1-(2-\gamma) a]}{9} ;$

$E\left[\Pi_{B} \mid s, D(1,1)\right]>E\left[\Pi_{B} \mid d, D(1,1)\right]$, and $E\left[\Pi_{B} \mid s, D(1,1)\right]>E\left[\Pi_{B} \mid 0, D(1,1)\right]$ iff $k_{1}^{B}<\frac{4 a \gamma[1-(1-\gamma) a]}{9}$

We can prove that $\frac{4 a h}{9}<\frac{4 a \gamma[1-(2-\gamma) a]}{9}<\frac{4 a \gamma[1-(1-\gamma) a]}{9}$ if $\gamma>\frac{2 a+\sqrt{1+4 a(a+h-1)}-1}{2 a}$, and $\frac{4 a \gamma[1-(2-\gamma) a]}{9}<$ $\frac{4 a h}{9}<\frac{4 a \gamma[1-(1-\gamma) a]}{9}$ if $\gamma<\frac{2 a+\sqrt{1+4 a(a+h-1)}-1}{2 a}$.

We set $K_{2}(\gamma)=\frac{4 a \gamma[1-(2-\gamma) a]}{9}$ and $\underline{\gamma}=\frac{2 a+\sqrt{1+4 a(a+h-1)}-1}{2 a}$, then we can obtain the following results:

if $k_{1}^{B}<\frac{4 a h}{9}$,which is Region II, $I_{B}^{*}(D)=s$ for $D=(1,1)$ or $(2,2)$, and $I_{B}^{*}(D)=d$ for $D=(2,1)$; if $\frac{4 a h}{9}<k_{1}^{B}<\operatorname{Min}\left\{K_{2}(\gamma), \bar{K}\right\}$, which is part of Region III, $I_{B}^{*}(D)=s$ for $D=(1,1)$ or $(2,2)$, and $I_{B}^{*}(D)=0$ for $D=(2,1)$

if $K_{2}(\gamma)<k_{1}^{B}<\bar{K}$, which is Region IV, $I_{B}^{*}(D)=s$ for $D=(1,1) ; I_{B}^{*}(D)=0$ for $D=(2,2)$ or $D=(2,1)$

Although we are not interested in the case that $\gamma<\underline{\gamma}$ in the paper, we still provide firm B's optimal strategy in this case below for completeness.

Firm B's optimal investment strategy when $\gamma<\underline{\gamma}$ :

1. When $\gamma_{2}<\gamma<\underline{\gamma}$,

if $k_{1}^{B}<K_{2}(\gamma), I_{B}^{*}(D)=s$ for $D=(1,1)$ or $(2,2)$, and $I_{B}^{*}(D)=d$ for $D=(2,1)$; 
if $K_{2}(\gamma)<k_{1}^{B}<\frac{4 a h}{9}, I_{B}^{*}(D)=s$ for $D=(1,1), I_{B}^{*}(D)=d$ for $D=(2,1)$, and $I_{B}^{*}(D)=0$ for $D=(2,2)$

if $\frac{4 a h}{9}<k_{1}^{B}<\operatorname{Min}\left\{\frac{4 a \gamma[1-(1-\gamma) a]}{9}, \bar{K}\right\}, I_{B}^{*}(D)=s$ for $D=(1,1)$, and $I_{B}^{*}(D)=0$ for $D=(2,1)$ or $D=(2,2)$.

2. When $\gamma_{3}<\gamma \leq \gamma_{2}$, we can prove that

$E\left[\Pi_{B} \mid d, D(2,1)\right]>E\left[\Pi_{B} \mid s, D(2,1)\right]$, and $E\left[\Pi_{B} \mid d, D(2,1)\right]>E\left[\Pi_{B} \mid 0, D(2,1)\right]$ iff $k_{1}^{B}<\frac{4 a h}{9} ;$

$E\left[\Pi_{B} \mid d, D(2,2)\right]>E\left[\Pi_{B} \mid s, D(2,2)\right]$, and $E\left[\Pi_{B} \mid d, D(2,2)\right]>E\left[\Pi_{B} \mid 0, D(2,2)\right]$ iff $k_{1}^{B}<\frac{4 a h(1-a)}{9} ;$

$E\left[\Pi_{B} \mid s, D(1,1)\right]>E\left[\Pi_{B} \mid d, D(1,1)\right]$, and $E\left[\Pi_{B} \mid s, D(1,1)\right]>E\left[\Pi_{B} \mid 0, D(1,1)\right]$ iff $k_{1}^{B}<\frac{4 a \gamma[1-(1-\gamma) a]}{9}$.

Therefore, we have the following results:

if $k_{1}^{B}<\frac{4 a h(1-a)}{9}, I_{B}^{*}(D)=s$ for $D=(1,1) ; I_{B}^{*}(D)=d$ for $D=(2,1)$ or $D=(2,2)$;

if $\frac{4 a h(1-a)}{9}<k_{1}^{B}<\frac{4 a h}{9}, I_{B}^{*}(D)=s$ for $D=(1,1), I_{B}^{*}(D)=d$ for $D=(2,1)$, and $I_{B}^{*}(D)=0$ for $D=(2,2)$

if $\frac{4 a h}{9}<k_{1}^{B}<\frac{4 a \gamma[1-(1-\gamma) a]}{9}, I_{B}^{*}(D)=s$ for $D=(1,1)$, and $I_{B}^{*}(D)=0$ for $D=(2,1)$ or $D=(2,2)$

if $\frac{4 a \gamma[1-(1-\gamma) a]}{9}<k_{1}^{B}<\bar{K}, I_{B}^{*}(D)=0$ for $D=(1,1), D=(2,1)$ or $D=(2,2)$.

3. When $0<\gamma \leq \gamma_{3}$, we can prove that

$E\left[\Pi_{B} \mid d, D\left(I_{A}, 1\right)\right]>E\left[\Pi_{B} \mid s, D\left(I_{A}, 1\right)\right]$, and $E\left[\Pi_{B} \mid d, D\left(I_{A}, 1\right)\right]>E\left[\Pi_{B} \mid 0, D\left(I_{A}, 1\right)\right]$ iff $k_{1}^{B}<\frac{4 a h}{9} ;$

$E\left[\Pi_{B} \mid d, D(2,2)\right]>E\left[\Pi_{B} \mid s, D(2,2)\right]$, and $E\left[\Pi_{B} \mid d, D(2,2)\right]>E\left[\Pi_{B} \mid 0, D(2,2)\right]$ iff $k_{1}^{B}<\frac{4 a h(1-a)}{9}$.

Therefore, we have the following results:

if $k_{1}^{B}<\frac{4 a h(1-a)}{9}, I_{B}^{*}(D)=d$ for $D=(1,1), D=(2,1)$ or $D=(2,2)$; 
if $\frac{4 a h(1-a)}{9}<k_{1}^{B}<\frac{4 a h}{9}, I_{B}^{*}(D)=d$ for $D=(1,1), D=(2,1)$, and $I_{B}^{*}(D)=0$ for $D=(2,2)$.

if $\frac{4 a h}{9}<k_{1}^{B}<\bar{K}, I_{B}^{*}(D)=0$ for $D=(1,1), D=(2,1)$ or $D=(2,2)$.

In the case $\gamma \leq \underline{\gamma}$, from the above results we can see that when firm $\mathrm{A}$ invests in two areas and reports under the successful-efforts method, $s$ is a dominated strategy for firm B. When firm A invests in one area and reports success, $s$ might be firm B's optimal strategy; however firm A will prefer the full-cost method by then to avoid firm B's imitating as proved in Section 3.2.2. Therefore in the equilibrium in this case, firm B will not follow firm A's investment because $\gamma$ is low and the spillover effect is very weak. We do not include the detailed analysis of this case in our main text because we focus on the imitating behavior of firm B.

\section{Proof of Lemma 2}

Proof. When firm A reports under the full-cost method and invests in one area, namely $D=(1, \emptyset)$, because

$$
\begin{aligned}
E\left[\Pi_{B} \mid d, D(1, \emptyset)\right]-E\left[\Pi_{B} \mid s, D(1, \emptyset)\right] & =\frac{4 a h\{1-\gamma+a[1-h+(1-\gamma) \gamma]\}}{9}>0 \\
\text { and } E\left[\Pi_{B} \mid d, D(1, \emptyset)\right]-E\left[\Pi_{B} \mid 0, D(1, \emptyset)\right] & =\frac{4 a h(1+a-a h)}{9}-k_{1}^{B}>0 \text { for } k_{1}^{B}<\bar{K}
\end{aligned}
$$

firm B's optimal investment decision is $d$.

When firm A reports under the full-cost method and invests in two areas, namely $D=(2, \emptyset)$, because

$$
\begin{aligned}
E\left[\Pi_{B} \mid d, D(2, \emptyset)\right]-E\left[\Pi_{B} \mid s, D(2, \emptyset)\right] & =\frac{4 a h\left\{1-\gamma+a\left[1-h(2-\gamma)+\gamma-\gamma^{2}\right]\right\}}{9}>0, \\
\text { and } E\left[\Pi_{B} \mid d, D(2, \emptyset)\right]-E\left[\Pi_{B} \mid 0, D(2, \emptyset)\right] & =\frac{4 a h(1+a-2 a h)}{9}-k_{1}^{B}>0 \text { for } k_{1}^{B}<\bar{K},
\end{aligned}
$$

firm B's optimal investment decision is $d$. 
Therefore, $I_{B}^{*}(D)=d$ is Firm B's optimal investment decision when Firm A reports under the full-cost method.

\section{Proof of Lemma 3}

Proof. In section 3.2.2, we proved that when $I_{A}=1$, the full-cost method is always the optimal reporting method for firm A. Here, we then solve firm A's optimal reporting method when $I_{A}=2$. When A reports under the full-cost method, according to Lemma $2, I_{B}^{*}(D)=d$ for $D=\left(I_{A}, \emptyset\right)$. We have

$E\left[\Pi_{A} \mid 2, F C\right]=h E\left[\Pi_{A} \mid I_{A}=2, a_{B}=a\right]+(1-h) E\left[\Pi_{A} \mid I_{A}=2, a_{B}=0\right]=\frac{1}{9}+\frac{2 a h}{3}+a^{2} h-k_{1}^{A}-k_{2}^{A}$.

When A reports under the successful-efforts method, because B's optimal strategy depends on $\gamma$ and $k_{1}^{B}$, we need to consider different regions of $\gamma$ and $k_{1}^{B}$.

(i) In Region I, according to Lemma $1, I_{B}^{*}(D)=s$ for $D=(2,1)$ or $(2,2)$, and $I_{B}^{*}(D)=d$ for $D=(2,0)$. We have

$$
\begin{aligned}
E\left[\Pi_{A} \mid 2, S E\right]= & h^{2} W_{A}(2 a, \gamma a)+(1-h)^{2}\left[h W_{A}(0, a)+(1-h) W_{A}(0,0)\right] \\
& +h(1-h)\left(W_{A}(a, \gamma a)+W_{A}(a, 0)\right)-k_{1}^{A}-k_{2}^{A} \\
= & \frac{1+a h\left\{2[3+(2-h) h-\gamma]+a\left[\left(3+h^{2}\right)-4(1+h) \gamma+\gamma^{2}\right]\right\}}{9}-k_{1}^{A}-k_{2}^{A} .
\end{aligned}
$$

It can be proved that $E\left[\Pi_{A} \mid 2, S E\right]<E\left[\Pi_{A} \mid 2, F C\right]$ in Region I. 
(ii) In Region II, according to Lemma $1, I_{B}^{*}(D)=s$ for $D=(2,2), I_{B}^{*}(D)=d$ for $D=(2,1)$, and $I_{B}^{*}(D)=d$ for $D=(2,0)$. We have

$$
\begin{aligned}
E\left[\Pi_{A} \mid 2, S E\right]= & h^{2} W_{A}(2 a, \gamma a)+(1-h)^{2}\left[h W_{A}(0, a)+(1-h) W_{A}(0,0)\right] \\
& +2 h(1-h)\left(h W_{A}(a, a)+(1-h) W_{A}(a, 0)\right)-k_{1}^{A}-k_{2}^{A} \\
= & \frac{1+a h\left\{2\left(3+h^{2}-h \gamma\right)+a\left[9+7 h^{2}-h(8-\gamma) \gamma\right]\right\}}{9}-k_{1}^{A}-k_{2}^{A} .
\end{aligned}
$$

It can be proved that $E\left[\Pi_{A} \mid 2, S E\right]<E\left[\Pi_{A} \mid 2, F C\right]$ in Region II.

(iii) In Region III, according to Lemma $1, I_{B}^{*}(D)=s$ for $D=(2,2), I_{B}^{*}(D)=0$ for $D=(2,1)$, and $I_{B}^{*}(D)=d$ for $D=(2,0)$. We have

$$
\begin{aligned}
E\left[\Pi_{A} \mid 2, S E\right] & =h^{2} W_{A}(2 a, \gamma a)+(1-h)^{2}\left[h W_{A}(0, a)+(1-h) W_{A}(0,0)\right]+2 h(1-h) W_{A}(a, 0)-k_{1}^{A}-k_{2}^{A} \\
& =\frac{1+a h\{6+4 h-2 h(h+\gamma)+a[9+h(6+h-(8-\gamma) \gamma)]\}}{9}-k_{1}^{A}-k_{2}^{A}
\end{aligned}
$$

It can be proved that $E\left[\Pi_{A} \mid 2, S E\right]>E\left[\Pi_{A} \mid 2, F C\right]$ in Region III.

(iv) In Region IV, according to Lemma $1, I_{B}^{*}(D)=0$ for $D=(2,2)$ or $(2,1)$, and $I_{B}^{*}(D)=d$ for $D=(2,0)$. We have

$$
\begin{aligned}
E\left[\Pi_{A} \mid 2, S E\right] & =h^{2} W_{A}(2 a, 0)+(1-h)^{2}\left[h W_{A}(0, a)+(1-h) W_{A}(0,0)\right]+2 h(1-h) W_{A}(a, 0)-k_{1}^{A}-k_{2}^{A} \\
& =\frac{1+a h\left[2(3-h)(1+h)+a(3+h)^{2}\right]}{9}-k_{1}^{A}-k_{2}^{A}
\end{aligned}
$$

It can be proved that $E\left[\Pi_{A} \mid 2, S E\right]>E\left[\Pi_{A} \mid 2, F C\right]$ in Region IV.

We define Region FC as the union of Regions I and II, and Region FC/SE as the union of Regions III and IV.

\section{Proof of Proposition 1}


Proof. We derive firm A's optimal investing and reporting strategy as well as B's optimal investing strategy in this proof.

We first prove that A will always invest under the assumption $k_{1}^{A}<\bar{K}$. In other words, not to invest is not A's optimal strategy.

According to Lemma 1 , if A does not invest at all $\left(I_{A}=x_{A}=0\right), I_{B}^{*}=d$. Therefore,

$$
E\left[\Pi_{A} \mid I_{A}=0\right]=h W_{A}(0, a)+(1-h) W_{A}(0,0)=\frac{1-(2-a) a h}{9} .
$$

In Section 3.2.2, we obtain $E\left[\Pi_{A} \mid 1, F C\right]=\frac{1-[2+a(5-4 h)] a h}{9}-k_{1}^{A}$. We can prove that $E\left[\Pi_{A} \mid 0, D\right]<$ $E\left[\Pi_{A} \mid 1, F C\right]$ when $k_{1}^{A}<\bar{K}$. Thus, for firm A, not investing is dominated by the strategy of investing in one area and using the full-cost method.

In Region FC, according to Lemma 3, A's optimal reporting method $R^{*}=F C$, and according to Lemma 2, B's optimal investing strategy $I_{B}^{*}=d$. We then compare $E\left[\Pi_{A} \mid 1, F C\right]$ with $E\left[\Pi_{A} \mid 2, F C\right]$, and find that $I_{A}^{*}=1$ if $k_{2}^{A}>\frac{4 a h(1+a+a h)}{9}$, and $I_{A}^{*}=2$ if $k_{2}^{A}<\frac{4 a h(1+a+a h)}{9}$.

In Region $F C / S E \cap I I I$, according to Lemma 3, A prefers the full-cost method if it invests in one area, and prefers the successful-efforts method if it invests in two areas. We then compare $E\left[\Pi_{A} \mid 1, F C\right]$ with $E\left[\Pi_{A} \mid 2, S E\right]$, and find that $\left(R^{*}, I_{A}^{*}\right)=(F C, 1)$ if $k_{2}^{A}>\frac{a h\{4(1+h)-2 h(h+\gamma)+a[4+h(10+h+(\gamma-8) \gamma)]\}}{9}$, and $\left(R^{*}, I_{A}^{*}\right)=(S E, 2)$ if $k_{2}^{A}<\frac{a h\{4(1+h)-2 h(h+\gamma)+a[4+h(10+h+(\gamma-8) \gamma)]\}}{9}$. According to Lemma 1 and Lemma 2, we obtain $I_{B}^{*}(D)=s$ for $D=(2,2), I_{B}^{*}(D)=0$ for $D=(2,1)$, and $I_{B}^{*}(D)=d$ for $D=(2,0)$ or $(1, \emptyset)$.

In Region $F C / S E \cap I V$, according to Lemma 3, A prefers the full-cost method if it invests in one area, and prefers the successful-efforts method if it invests in two areas. We then compare $E\left[\Pi_{A} \mid 1, F C\right]$ with $E\left[\Pi_{A} \mid 2, S E\right]$, and find that $\left(R^{*}, I_{A}^{*}\right)=(F C, 1)$ if $k_{2}^{A}>\frac{a h\{4+2(2-h) h+a[4+h(10+h)]\}}{9}$, and $\left(R^{*}, I_{A}^{*}\right)=(S E, 2)$ if $k_{2}^{A}<\frac{a h\{4+2(2-h) h+a[4+h(10+h)]\}}{9}$. According to Lemma 1 and Lemma 2 , 
we obtain $I_{B}^{*}(D)=0$ for $D=(2,2)$ or $(2,1)$, and $I_{B}^{*}(D)=d$ for $D=(2,0)$ or $(1, \emptyset)$.

We summarize all the thresholds for firm A's cost in A's investment decision by defining $K_{A}\left(\gamma, k_{1}^{B}\right)$ as

$$
K_{A}\left(\gamma, k_{1}^{B}\right)= \begin{cases}\frac{4 a h(1+a+a h)}{9}, & \text { for Region } F C, \\ \frac{a h[4(1+h)-2 h(h+\gamma)+4 a+a h(10+h+(\gamma-8) \gamma)]}{9}, & \text { for Region } F C / S E \cap I I I, \\ \frac{a h\{4+2(2-h) h+a[4+h(10+h)]\}}{9}, & \text { for Region } F C / S E \cap I V .\end{cases}
$$

\section{Proof of Lemma 4}

Proof. When the successful-efforts method is enforced, we compare A's expected payoffs with no investment $E\left[\Pi_{A} \mid 0, D\right]$, one investment $E\left[\Pi_{A} \mid 1, S E\right]$, and two investments $E\left[\Pi_{A} \mid 2, S E\right]$, and then find A's optimal investing strategy.

As derived in the proof of Proposition $1, E\left[\Pi_{A} \mid 0, D\right]=\frac{1-(2-a) a h}{9}$.

As derived in Section 3.2.2,

$$
E\left[\Pi_{A} \mid 1, S E\right]=\frac{1+\{2(1+h-\gamma)+a[5-h-(4-\gamma) \gamma]\} a h}{9}-k_{1}^{A} .
$$

As derived in the proof of Lemma 3,

$$
E\left[\Pi_{A} \mid 2, S E\right]= \begin{cases}\frac{1+a h\left\{2[3+(2-h) h-\gamma]+a\left[(3+h)^{2}-4(1+h) \gamma+\gamma^{2}\right]\right\}}{9}-k_{1}^{A}-k_{2}^{A} . & \text { for Region I, } \\ \frac{1+a h\left\{2\left(3+h^{2}-h \gamma\right)+a\left[9+7 h^{2}-h(8-\gamma) \gamma\right]\right\}}{9}-k_{1}^{A}-k_{2}^{A} & \text { for Region II, } \\ \frac{1+a h\{6+4 h-2 h(h+\gamma)+a[9+h(6+h-(8-\gamma) \gamma)]\}}{9}-k_{1}^{A}-k_{2}^{A} & \text { for Region III } \\ \frac{1+a h\left[2(3-h)(1+h)+a(3+h)^{2}\right]}{9}-k_{1}^{A}-k_{2}^{A} . & \text { for Region IV. }\end{cases}
$$

It can be easily proved that $E\left[\Pi_{A} \mid 1, S E\right]>E\left[\Pi_{A} \mid 0, D\right]$ iff $k_{1}^{A}<\frac{a h\left\{2(2+h-\gamma)-a\left[h-(2-\gamma)^{2}\right]\right\}}{9}$. Setting $K_{1}^{A}=\frac{a h\left\{2(2+h-\gamma)-a\left[h-(2-\gamma)^{2}\right]\right\}}{9}$, we can prove that $K_{1}^{A}<\bar{K}$.

If $k_{1}^{A}<K_{1}^{A}$, as derived above, investing in one area is a better strategy than no investment. Then we compare $E\left[\Pi_{A} \mid 2, S E\right]$ with $E\left[\Pi_{A} \mid 1, S E\right]$, and find there is a threshold $K_{A}^{S E}\left(\gamma, k_{1}^{A}, k_{1}^{B}\right)$, that A prefers to invest in one area if $k_{2}^{A}>K_{A}^{S E}\left(\gamma, k_{1}^{A}, k_{1}^{B}\right)$, and prefers to invest in two areas if 
$k_{2}^{A}<K_{A}^{S E}\left(\gamma, k_{1}^{A}, k_{1}^{B}\right)$.

If $k_{1}^{A}>K_{1}^{A}$, no investment is a better strategy than investing in one area. Then we compare $E\left[\Pi_{A} \mid 2, S E\right]$ with $E\left[\Pi_{A} \mid 0\right]$, and find there is a threshold $K_{A}^{S E}\left(\gamma, k_{1}^{A}, k_{1}^{B}\right)$, that A prefers not to invest if $k_{2}^{A}>K_{A}^{S E}\left(\gamma, k_{1}^{A}, k_{1}^{B}\right)$, and prefers to invest in two areas if $k_{2}^{A}<K_{A}^{S E}\left(\gamma, k_{1}^{A}, k_{1}^{B}\right)$.

The closed-form expression of $K_{A}^{S E}\left(\gamma, k_{1}^{A}, k_{1}^{B}\right)$ is:

$$
K_{A}^{S E}\left(\gamma, k_{1}^{A}, k_{1}^{B}\right)= \begin{cases}\frac{2(2-h)(1+h)+a[4+h(7+h-4 \gamma)]}{9 /(a h)} & \text { for Region } I \text { and } k_{1}^{A}<K_{A}, \\ \frac{a\left[4+h+7 h^{2}+(4-8 h) \gamma-(1-h) \gamma^{2}\right]+2\left[2+h^{2}+\gamma-h(1+\gamma)\right]}{9 /(a h)} & \text { for Region } I I \text { and } k_{1}^{A}<K_{A}, \\ \frac{2(1-h)(h+\gamma)+4+a\left[4+h^{2}+h(7-\gamma)(1-\gamma)+(4-\gamma) \gamma\right]}{9 /(a h)} & \text { for Region III and } k_{1}^{A}<K_{A}, \\ \frac{a h\left\{2[4+(2-h) h+\gamma]+a\left[8+6 h+h^{2}-4(1+h) \gamma+\gamma^{2}\right]\right\}}{9}-k_{1}^{A} & \text { for Region } I \text { and } k_{1}^{A}>K_{A}, \\ \frac{a h\left\{2\left(h^{2}-h \gamma+4\right)+a\left[8+7 h^{2}-h(8-\gamma) \gamma\right]\right\}}{9}-k_{1}^{A} & \text { for Region } I I \text { and } k_{1}^{A}>K_{A}, \\ \frac{a h\{4(2+h)-2 h(h+\gamma)+a[8+h(6+h-(8-\gamma) \gamma)]\}}{9}-k_{1}^{A} & \text { for Region } I I I \text { and } k_{1}^{A}>K_{A}, \\ \frac{a h[8+2(2-h) h+a(2+h)(4+h)]}{9}-k_{1}^{A} & \text { for Region } I V \text { and } k_{1}^{A}>K_{A},\end{cases}
$$

\section{Proof of Proposition 2}

Proof. When the successful-efforts method is enforced, we have derived A's optimal investing strategy in Lemma 4.

For $k_{1}^{A}<K_{1}^{A}$, we can prove $K_{A}^{S E}\left(\gamma, k_{1}^{A}, k_{1}^{B}\right)>K_{A}\left(\gamma, k_{1}^{B}\right)$. Therefore, firm A's number of investment increases from one area to two areas if $K_{A}\left(\gamma, k_{1}^{B}\right)<k_{2}^{A}<K_{A}^{S E}\left(\gamma, k_{1}^{A}, k_{1}^{B}\right)$ after the enforcement of the successful-efforts method, and does not change otherwise.

For $K_{1}^{A}<k_{1}^{A}<\bar{K}$, if $\gamma, k_{1}^{B}$ are in Regions $I$ and $I I$ (which is Region $F C$ ), we can prove $K_{A}^{S E}\left(\gamma, k_{1}^{A}, k_{1}^{B}\right)<K_{1}^{A}$. Because we assume that $\mathrm{A}$ has a convex investment-cost function, namely $k_{2}^{A}>k_{1}^{A}$, we have $k_{2}^{A}>K_{A}^{S E}\left(\gamma, k_{1}^{A}, k_{1}^{B}\right)$. Therefore, firm A doesn't invest at all when the successfulefforts reporting method is enforced. If $\gamma, k_{1}^{B}$ are in Regions $I I I$ and $I V$ (which is Region FC/SE), we can prove $K_{A}^{S E}\left(\gamma, k_{1}^{A}, k_{1}^{B}\right)>K_{A}\left(\gamma, k_{1}^{B}\right)$. Therefore, after the enforcement of the successful-efforts 
reporting method, firm A's number of investment increases from one to two if $K_{A}\left(\gamma, k_{1}^{B}\right)<k_{2}^{A}<$ $K_{A}^{S E}\left(\gamma, k_{1}^{A}, k_{1}^{B}\right)$, decreases from one to zero if $k_{2}^{A}>K_{A}^{S E}\left(\gamma, k_{1}^{A}, k_{1}^{B}\right)$, and does not change otherwise.

\section{Proof of Proposition 3}

Proof. When the full-cost reporting method is enforced, as shown in the proof of Proposition 1, $E\left[\Pi_{A} \mid 0, D\right]<E\left[\Pi_{A} \mid 1, F C\right]$, firm A will invest in at least one area.

We have already derived $E\left[\Pi_{A} \mid 1, F C\right]$ and $E\left[\Pi_{A} \mid 2, F C\right]$ 's value in the proof of Proposition 1 and Lemma 3. Comparing $E\left[\Pi_{A} \mid 1, F C\right]$ with $E\left[\Pi_{A} \mid 2, F C\right]$, we find that $E\left[\Pi_{A} \mid 1, F C\right]<E\left[\Pi_{A} \mid 2, F C\right]$ if $k_{2}^{A}>\frac{4 a h(1+a+a h)}{9}$, and $E\left[\Pi_{A} \mid 1, F C\right]<E\left[\Pi_{A} \mid 2, F C\right]$ if $k_{2}^{A}<\frac{4 a h(1+a+a h)}{9}$.

Setting $K_{A}^{F C}=\frac{4 a h(1+a+a h)}{9}$, we can prove that $K_{A}\left(\gamma, k_{1}^{B}\right)=K_{A}^{F C}$ in Region $F C ; K_{A}\left(\gamma, k_{1}^{B}\right)>$ $K_{A}^{F C}$ in Region $F C / S E$.

Therefore, in Region FC, enforcing the full-cost method does not affect firm A's investment; in Region $F C / S E$, A's number of investments reduces from two to one after enforcing the full-cost method if $K_{A}^{F C}<k_{2}^{A}<K_{A}\left(\gamma, k_{1}^{B}\right)$, and does not change otherwise.

\section{Proof of Lemma 5}

Proof. In the alternative setup, $I_{A} \in\{0,1\}, \widehat{x}_{A} \in\{0,1, \emptyset\}$ and $I_{B}^{*}(D) \in\{s, d, s d, d d\}$, where $s d$ means firm B invests in both A's area and an additional area, $d d$ means firm B invests in two areas different from A's investment, and $s$ and $d$ are the same as those in the main setup.

When A reports under the successful-efforts method, we compare firm B's expected payoffs of all four possible investment strategies, $I_{B} \in\{s, d, s d, d d\}$, based on firm A's report $D\left(I_{A}, \widehat{x}_{A}\right)$, and then we solve for firm B's optimal strategy $I_{B}^{*}(D)$.

1. If firm A reports failure $(D=(1,0))$, or does not invest at all, it's easy to prove $I_{B}^{*}(D)=d d$ under assumption $k_{2}^{B}<\overline{K_{2}^{B}}$. 
2. If firm A reports $\operatorname{success}(D=(1,1))$, firm B's expected payoffs by different investment strategies are

$$
\begin{aligned}
E\left[\Pi_{B} \mid s, D(1,1)\right] & =W_{B}(\gamma a, a)=\frac{(1-a+2 a \gamma)^{2}}{9}-k_{1}^{B} \\
E\left[\Pi_{B} \mid d, D(1,1)\right] & =h W_{B}(a, a)+(1-h) W_{B}(0, a)=\frac{(1-a)^{2}+4 a h}{9}-k_{1}^{B} \\
E\left[\Pi_{B} \mid s d, D(1,1)\right] & =h W_{B}(\gamma a+a, a)+(1-h) W_{B}(\gamma a, a)-k_{1}^{B}-k_{2}^{B} \\
& =\frac{1+a\{-2+4 h+4 \gamma+a[1+4 \gamma(2 h+\gamma-1)]\}}{9}-k_{1}^{B}-k_{2}^{B} ; \\
E\left[\Pi_{B} \mid d d, D(1,1)\right] & =h^{2} W_{B}(2 a, a)+(1-h)^{2} W_{B}(0, a)+2 h(1-h) W_{B}(a, a)-k_{1}^{B}-k_{2}^{B} \\
& =\frac{1+a\left(a+8 h+8 a h^{2}-1\right)}{9}-k_{1}^{B}-k_{2}^{B} .
\end{aligned}
$$

As in the main setup, we only consider the case $\underline{\gamma}<\gamma<1$, and obtain that $E\left[\Pi_{B} \mid s, D(1,1)\right]>$ $E\left[\Pi_{B} \mid d, D(1,1)\right]>0$ and $E\left[\Pi_{B} \mid s d, D(1,1)\right]>E\left[\Pi_{B} \mid d d, D(1,1)\right]$

Because $E\left[\Pi_{B} \mid s d, D(1,1)\right]-E\left[\Pi_{B} \mid s, D(1,1)\right]=\frac{4 a h(1+2 a \gamma)}{9}-k_{2}^{B}$, we derive that for $D=(1,1), I_{B}^{*}(D)=$ $s d$ if $k_{2}^{B}<\operatorname{Min}\left\{\frac{4 a h(1+2 a \gamma)}{9}, \overline{K_{2}^{B}}\right\}$, namely $k_{2}^{B}<\frac{4 a h(1+2 a \gamma)}{9}$ or $\frac{1+h}{2}<\gamma<1$; and $I_{B}^{*}(D)=s$ if $\overline{K_{2}^{B}}>k_{2}^{B}>\frac{4 a h(1+2 a \gamma)}{9}$ and $\underline{\gamma}<\gamma<\frac{1+h}{2}$.

\section{Proof of Lemma 6}

Proof. When A reports under the full-cost method, we compare firm B's expected payoffs of all four possible investment strategies, $I_{B} \in\{s, d, s d, d d\}$, given firm A's report $D(1, \emptyset)$, in order to 
find firm B's optimal strategy $I_{B}^{*}(D)$. We have

$$
\begin{aligned}
E\left[\Pi_{B} \mid s, D(1, \emptyset)\right]= & h W_{B}(\gamma a, a)+(1-h) W_{B}(0,0)-k_{1}^{B}=\frac{1-h-h(1-a+2 a \gamma)^{2}}{9}-k_{1}^{B} ; \\
E\left[\Pi_{B} \mid d, D(1, \emptyset)\right]= & h^{2} W_{B}(a, a)+(1-h)^{2} W_{B}(0,0)+h(1-h)\left[W_{B}(0, a)+W_{B}(a, 0)\right]-k_{1}^{B} ; \\
= & \frac{1+a[2+a(5-4 h)] h}{9}-k_{1}^{B} ; \\
E\left[\Pi_{B} \mid s d, D(1, \emptyset)\right]= & h\left(h W_{B}(a+\gamma a, a)+(1-h) W_{B}(a, 0)\right)+(1-h) E\left[\Pi_{B} \mid s, D(1, \emptyset)\right]-k_{1}^{B}-k_{2}^{B} \\
= & \frac{1+a h\{2+4 \gamma+a[5-4(1-\gamma) \gamma-h(4-8 \gamma)]\}}{9}-k_{1}^{B}-k_{2}^{B} ; \\
E\left[\Pi_{B} \mid d d, D(1, \emptyset)\right]= & h^{2}\left(h W_{B}(2 a, a)+(1-h) W_{B}(2 a, 0)\right)+(1-h)^{2}\left(h W_{B}(0, a)+(1-h) W_{B}(0,0)\right) \\
& +2 h(1-h)\left(h W_{B}(a, a)+(1-h) W_{B}(a, 0)\right)-k_{1}^{B}-k_{2}^{B} \\
= & \frac{1}{9}+\frac{2 a h}{3}+a^{2} h-k_{1}^{B}-k_{2}^{B} .
\end{aligned}
$$

We can prove that $E\left[\Pi_{B} \mid d, D(1, \emptyset)\right]>E\left[\Pi_{B} \mid s, D(1, \emptyset)\right]>0$ and $E\left[\Pi_{B} \mid d d, D(1, \emptyset)\right]>E\left[\Pi_{B} \mid s d, D(1, \emptyset)\right]$.

Because $E\left[\Pi_{B} \mid d d, D(1, \emptyset)\right]-E\left[\Pi_{B} \mid d, D(1, \emptyset)\right]=\frac{4 a h(1+a+a h)}{9}-k_{2}^{B}$, under the assumption $k_{2}^{B}<$ $\overline{K_{2}^{B}}$, firm B's optimal strategy when A reports under the full-cost regime is to invest in two areas different from A, namely $I_{B}^{*}(D)=d d$ for $D=(1, \emptyset)$.

\section{Proof of Proposition 4}

Proof. We now derive firm A's optimal investing and reporting strategy as well as B's optimal investing strategy.

Firstly we calculate firm A's expected payoffs of different investing and reporting strategies given $I_{B}^{*}(D)$ derived in Lemma 5 and Lemma 6 .

If $\mathrm{A}$ does not invest, we have

$$
E\left[\Pi_{A} \mid 0\right]=h^{2} W_{A}(0,2 a)+(1-h)^{2} W(0,0)+2 h(1-h) W_{A}(0, a)=\frac{1+2 a h(a+a h-2)}{9} .
$$


If $\mathrm{A}$ invests and reports under the full-cost regime, we have

$$
\begin{aligned}
E\left[\Pi_{A} \mid 1, F C\right] & =h\left(h^{2} W_{A}(a, 2 a)+(1-h)^{2} W(a, 0)+2 h(1-h) W_{A}(a, a)\right)+(1-h) E\left[\Pi_{A} \mid 0\right]-k_{1}^{A} \\
& =\frac{1+6 a^{2} h(1-h)}{9}-k_{1}^{A} .
\end{aligned}
$$

If $\mathrm{A}$ invests and reports under the successful-efforts regime,

(i) when $k_{2}^{B}<\frac{4 a h(1+2 a \gamma)}{9}$, we have

$$
\begin{aligned}
E\left[\Pi_{A} \mid 1, S E\right] & =h\left(h W_{A}(a, a+\gamma a)+(1-h) W_{A}(a, \gamma a)\right)+(1-h) E\left[\Pi_{A} \mid 0\right]-k_{1}^{A} \\
& =\frac{1+a h\left\{2(h-\gamma)+a\left[6-2 h^{2}-(4-\gamma) \gamma-h(3-2 \gamma)\right]\right\}}{9}-k_{1}^{A} .
\end{aligned}
$$

(ii) when $k_{2}^{B}>\frac{4 a h(1+2 a \gamma)}{9}$, we have

$$
\begin{aligned}
E\left[\Pi_{A} \mid 1, S E\right] & =h W_{A}(a, \gamma a)+(1-h) E\left[\Pi_{A} \mid 0\right]-k_{1}^{A} \\
& =\frac{1+a h\left\{4 h-2 \gamma+a\left[6-2 h^{2}-(4-\gamma) \gamma\right]\right\}}{9}-k_{1}^{A} .
\end{aligned}
$$

Secondly, we compare firm A's expected payoffs with different investing and reporting strategies to derive firm A's optimal strategy.

It can be proved that $E\left[\Pi_{A} \mid 1, F C\right]>E\left[\Pi_{A} \mid 0\right]$. Therefore, no investment is a dominated strategy for A.

When $k_{2}^{B}<\frac{4 a h(1+2 a \gamma)}{9}$, we can prove that $E\left[\Pi_{A} \mid 1, F C\right]>E\left[\Pi_{A} \mid 1, S E\right]$. Thus, firm A optimally invests in one area and chooses the full-cost method, namely $\left(R^{*}, I_{A}^{*}\right)=(F C, 1)$. 
When $k_{2}^{B}>\frac{4 a h(1+2 a \gamma)}{9}$, we can prove that

$$
\begin{aligned}
& E\left[\Pi_{A} \mid 1, F C\right]>E\left[\Pi_{A} \mid 1, S E\right] \text { if } \gamma>\frac{2 a-\sqrt{1+2 a(2+a(2-h))(1-h)}+1}{a}, \text { and } \\
& E\left[\Pi_{A} \mid 1, F C\right]<E\left[\Pi_{A} \mid 1, S E\right] \text { if } \gamma<\frac{2 a-\sqrt{1+2 a(2+a(2-h))(1-h)}+1}{a}
\end{aligned}
$$

Set $\widehat{\gamma_{1}}=\frac{2 a-\sqrt{1+2 a(2+a(2-h))(1-h)}+1}{a}$, and we can conclude the above results in Proposition 4 .

\section{Proof of Proposition 5}

Proof. When the successful-efforts method is enforced, we have obtained the values of $E\left[\Pi_{A} \mid 1, S E\right]$ and $E\left[\Pi_{A} \mid 0\right]$ in the proof of Proposition 4. Comparing $E\left[\Pi_{A} \mid 1, S E\right]$ with $E\left[\Pi_{A} \mid 0\right]$, we have

$$
E\left[\Pi_{A} \mid 1, S E\right]-E\left[\Pi_{A} \mid 0\right]=\left\{\begin{array}{cl}
\frac{a h\left\{2(2+h-\gamma)+a\left[(2-\gamma)^{2}-h(5-2 \gamma)-2 h^{2}\right]\right\}}{9} & \text { if } k_{2}^{B}<\frac{4 a h(1+2 a \gamma)}{9} \text { or } \frac{1+h}{2}<\gamma<1, \\
\frac{a h\left\{4+4 h+a\left[(2-\gamma)^{2}-2 h(1+h)\right]-2 \gamma\right\}}{9} & \text { if } \overline{K_{2}^{B}}>k_{2}^{B}>\frac{4 a h(1+2 a \gamma)}{9} \text { and } \underline{\gamma}<\gamma<\frac{1+h}{2} .
\end{array}\right.
$$

We can prove that $\frac{a h\left\{2(2+h-\gamma)+a\left[(2-\gamma)^{2}-h(5-2 \gamma)-2 h^{2}\right]\right\}}{9}<\bar{K} ; \frac{a h\left\{4+4 h+a\left[(2-\gamma)^{2}-2 h(1+h)\right]-2 \gamma\right\}}{9}>\bar{K}$ if $\underline{\gamma}<\gamma<\widehat{\gamma_{1}}$, and $\frac{a h\left\{4+4 h+a\left[(2-\gamma)^{2}-2 h(1+h)\right]-2 \gamma\right\}}{9}<\bar{K}$ if $\widehat{\gamma_{1}}<\gamma<\frac{1+h}{2}$.

By defining $K_{1}^{A, S E}\left(\gamma, k_{2}^{B}\right)$ as follows, we could summarize all the thresholds for firm A's cost in its investment decision in the alternative setup when the successful-efforts reporting method is enforced as

$$
K_{1}^{A, S E}\left(\gamma, k_{2}^{B}\right)=\left\{\begin{array}{cc}
\frac{a h\left\{2(2+h-\gamma)+a\left[-2 h^{2}+(-2+\gamma)^{2}+h(-5+2 \gamma)\right]\right\}}{9} & \text { if } k_{2}^{B}<\frac{4 a h(1+2 a \gamma)}{9} \text { or } \frac{1+h}{2}<\gamma<1, \\
\bar{K} & \text { if } \overline{K_{2}^{B}}>k_{2}^{B}>\frac{4 a h(1+2 a \gamma)}{9} \text { and } \underline{\gamma}<\gamma<\widehat{\gamma_{1}}, \\
\frac{a h\left\{4+4 h+a\left[-2 h(1+h)+(-2+\gamma)^{2}\right]-2 \gamma\right\}}{9} & \text { if } \overline{K_{2}^{B}}>k_{2}^{B}>\frac{4 a h(1+2 a \gamma)}{9} \text { and } \widehat{\gamma_{1}}<\gamma<\frac{1+h}{2} .
\end{array}\right.
$$

When the successful-efforts method is enforced, firm A invests if $k_{1}^{A}<K_{1}^{A, S E}\left(\gamma, k_{2}^{B}\right)$, and does not invest if $K_{1}^{A, S E}\left(\gamma, k_{2}^{B}\right)<k_{1}^{A}<\bar{K}$. Recall that as derived in Proposition 4, A always invests under the discretionary-reporting regime. Therefore, enforcing the successful-efforts method would induce A to reduce its investment if $K_{1}^{A, S E}\left(\gamma, k_{2}^{B}\right)<k_{1}^{A}<\bar{K}$.

\section{Proof of Proposition 6}


Proof. When the full-cost method is enforced, we have obtained the values of $E\left[\Pi_{A} \mid 1, F C\right]$ and $E\left[\Pi_{A} \mid 0\right]$ in the proof of Proposition 4.

We have $E\left[\Pi_{A} \mid 1, F C\right]-E\left[\Pi_{A} \mid 0\right]=\frac{4 a h(1+a-2 a h)}{9}-k_{1}^{A}>0$ for $k_{1}^{A}<\bar{K}$.

Therefore, firm A always invests, and the enforcement of the full-cost method does not affect A's amount of investment.

\section{Appendix II: Bertrand Competition model}

We now study a Bertrand competition market in which the firm's successful exploration reduces its production cost. The payoff functions of firms A and B are, respectively:

$$
\begin{aligned}
& \Pi_{A}=\left[p_{A}-\left(c-a_{A}\right)\right]\left(1-p_{A}+p_{B}\right)-k_{1}^{A}-k_{2}^{A} t_{A}, \\
& \Pi_{B}=\left[p_{B}-\left(c-a_{B}\right)\right]\left(1-p_{B}+p_{A}\right)-k_{1}^{B} t_{B},
\end{aligned}
$$

where $a_{i}$ is firm $i$ 's production-cost reduction obtained through successful exploration; $p_{i}$ is firm $i$ 's price decision; $c$ is the initial production cost for both firms without any successful explorations; and $1-p_{i}+p_{j}$ represents firm $i$ 's market demand for $i \in\{A, B\}$.

Taking the first-order condition of $\Pi_{i}$ with respect to $p_{i}$, we can solve the Bertrand model and

obtain firm $i$ 's optimal price $p_{i}^{*}=c+1-\frac{2 a_{i}}{3}-\frac{a_{j}}{3}$, and gross payoff with out considering the investment/exploration cost,

$$
W_{i}\left(a_{i}, a_{j}\right)=\left[p_{i}^{*}-\left(c-a_{i}\right)\right]\left(1-p_{i}^{*}+p_{j}^{*}\right)=\frac{\left(3+a_{i}-a_{j}\right)^{2}}{9} .
$$

As in the main setting, we make some assumptions about several parameters to exclude uninteresting cases. We assume that A's exploration cost cannot be extremely large, such that when the successful-efforts regime is enforced, firm A as a large firm invests in at least one area. We assume that B's exploration cost is not very large as well, such that when A uses the full-cost method and 
invests in two areas, B will invest. To be more specific, we assume $k_{1}^{A}<\bar{K}_{A}$ and $k_{1}^{B}<\bar{K}_{B} \cdot{ }^{16}$ We also assume that $\gamma$ is not very small $\left(\gamma>\underline{\gamma^{\prime}}\right)$, such that firm B has an incentive to follow A's investment in the equilibrium. ${ }^{17}$

With similar methodology as in the main setting, we can solve B 's optimal investment decision upon A's report. The results are almost the same as in Lemmas 1 and 2, except for the close forms of regions that delimit B's strategies:

Region I is $k_{1}^{B}<\operatorname{Min}\left\{\bar{K}_{B}, K_{1}^{\prime}(\gamma)\right\}$ and $\gamma_{1}^{\prime}<\gamma<1$;

Region II is $k_{1}^{B}<\frac{(6-a) a h}{9}$ and $\underline{\gamma}^{\prime}<\gamma<\gamma_{1}^{\prime}$;

Region III is $\operatorname{Max}\left\{\frac{(6-a) a h}{9}, K_{1}^{\prime}(\gamma)\right\}<k_{1}^{B}<\operatorname{Min}\left\{\bar{K}_{B}, K_{2}^{\prime}(\gamma)\right\}$;

Region IV is $K_{2}^{\prime}(\gamma)<k_{1}^{B}<\bar{K}$ and $\underline{\gamma}^{\prime}<\gamma<1$. ${ }^{18}$

Firm B's optimal strategies when firm A reports using the successful-efforts method are summarized in the following table:

\begin{tabular}{|l|c|l|l|l|}
\hline & $D=(1,0)$ or $(2,0)$ & $D=(1,1)$ & $D=(2,1)$ & $D=(2,2)$ \\
\hline Region I & $I_{B}^{*}(D)=d$ & $I_{B}^{*}(D)=s$ & $I_{B}^{*}(D)=s$ & $I_{B}^{*}(D)=s$ \\
\hline Region II & $I_{B}^{*}(D)=d$ & $I_{B}^{*}(D)=s$ & $I_{B}^{*}(D)=d$ & $I_{B}^{*}(D)=s$ \\
\hline Region III & $I_{B}^{*}(D)=d$ & $I_{B}^{*}(D)=s$ & $I_{B}^{*}(D)=0$ & $I_{B}^{*}(D)=s$ \\
\hline Region IV & $I_{B}^{*}(D)=d$ & $I_{B}^{*}(D)=s$ & $I_{B}^{*}(D)=0$ & $I_{B}^{*}(D)=0$ \\
\hline
\end{tabular}

Firm B optimally invests in a different area if A reports under the full-cost method.

Given B's optimal investment strategy upon A's report, we could derive A's optimal accountingreporting method choice and exploration investment. We obtain similar results as Proposition 1, in the equilibrium,

\footnotetext{
${ }^{16} \bar{K}_{A}=\frac{1}{9} a h\left\{a\left[(1-\gamma)^{2}-h\right]+6(1+h-\gamma)\right\}, \bar{K}_{B}=\frac{1}{9} a h(6+a-a h)$.

${ }^{17} \underline{\gamma}^{\prime}=2-\frac{3-\sqrt{(3-2 a)^{2}+(6-a) a h}}{a}$.

${ }^{18} K_{1}^{\prime}(\gamma)=\frac{a \gamma[6-a(2-\gamma)]}{18}, \gamma_{1}^{\prime}=\frac{a-3+\sqrt{(3-a)^{2}+2 a h(6-a)}}{a} ; K_{2}^{\prime}(\gamma)=\frac{a[6-(4-\gamma)]}{9}$.
} 
(i) for Region I and Region II, firm A chooses to report under the full-cost method and firm B always explores a different area. Firm A explores one area if $k_{1}^{A}>K_{A}^{\prime}\left(\gamma, k_{1}^{B}\right)$ and explores two areas if $k_{1}^{A}<K_{A}^{\prime}\left(\gamma, k_{1}^{B}\right)$;

(ii) for Region III, firm A chooses to invest in one area using the full-cost method if $k_{1}^{A}>$ $K_{A}^{\prime}\left(\gamma, k_{1}^{B}\right)$, and invests in two areas using the successful-efforts method if $k_{1}^{A}<K_{A}^{\prime}\left(\gamma, k_{1}^{B}\right)$. B invests in a different area if A reports no success or chooses the full-cost method, invests in a same area if A reports full success, and does not invest at all if A reports partial success;

(iii) for Region IV, firm A chooses to invest in one area using the full-cost method if $k_{1}^{A}>$ $K_{A}^{\prime}\left(\gamma, k_{1}^{B}\right)$, and invests in two areas using the successful-efforts method if $k_{1}^{A}<K_{A}^{\prime}\left(\gamma, k_{1}^{B}\right)$. B invests in a different area if A reports no success or chooses the full-cost method, in a same area if A reports success in its only investment, and does not invest at all if A reports any success out of two investments. ${ }^{19}$

Then we compare A's optimal investment strategy when the successful-efforts method is enforced. In this case, A invests in two areas if $k_{1}^{A}<K_{A}^{S E^{\prime}}\left(\gamma, k_{1}^{B}\right)$ and invests in one area if $k_{1}^{A}>K_{A}^{S E^{\prime}}\left(\gamma, k_{1}^{B}\right) \cdot{ }^{20}$ We can prove that $K_{A}^{\prime}\left(\gamma, k_{1}^{B}\right)<K_{A}^{S E^{\prime}}\left(\gamma, k_{1}^{B}\right)$. Therefore, for firms with $K_{A}^{\prime}\left(\gamma, k_{1}^{B}\right)<k_{1}^{A}<K_{A}^{S E^{\prime}}\left(\gamma, k_{1}^{B}\right)$, enforcing the successful-efforts method induces them to increase exploration investment; for firms with $k_{1}^{A}<K_{A}^{\prime}\left(\gamma, k_{1}^{B}\right)$ or $k_{1}^{A}>K_{A}^{S E^{\prime}}\left(\gamma, k_{1}^{B}\right)$, their exploration investment does not change after the enforcement of the successful-efforts method.

When the full-cost method is enforced, firm A invests in two areas if $k_{1}^{A}<K_{A}^{F C^{\prime}}=a h(6+a) / 9$, and in one area otherwise. We can prove that $K_{A}^{\prime}\left(\gamma, k_{1}^{B}\right) \geqslant K_{A}^{F C^{\prime}}$. Therefore, for firms with $K_{A}^{F C^{\prime}}<k_{1}^{A}<K_{A}^{\prime}\left(\gamma, k_{1}^{B}\right)$, enforcing the full-cost method induces them to decrease exploration

$$
\begin{gathered}
{ }^{19} K_{A}^{\prime}\left(\gamma, k_{1}^{B}\right)=\left\{\begin{array}{cc}
a h(6+a) / 9, & \text { Region I, II } \\
a h\{6+12 h-6 h(h+\gamma)+a[1+h(2+h-\gamma(4-\gamma))]\} / 9, & \text { Region III } \\
a h\left[6+6 h(2-h)+a(1+h)^{2}\right] / 9 . & \text { Region IV } \\
a h\left[6+6 h(1-h)+a\left(1+h+h^{2}-2 h \gamma\right)\right] / 9, & \text { Region I }
\end{array}\right. \\
{ }^{20} K_{A}^{S E^{\prime}}\left(\gamma, k_{1}^{B}\right)=\left\{\begin{array}{cc}
a h\left\{6\left[1+\gamma+h^{2}-h(1+\gamma)\right]+a\left[1+3 h^{2}+\gamma(2-\gamma)-h(1+\gamma(4-\gamma))\right]\right\}, & \text { Region II } \\
a h\left\{6[1+(1-h)(h+\gamma)]+a\left[1+h+h^{2}+\gamma(2-4 h)-\gamma^{2}(1-h)\right]\right\} / 9, & \text { Region III } \\
a h\left\{6\left(1+h+\gamma-h^{2}\right)+a\left[1+h+h^{2}+\gamma(2-\gamma)\right]\right\} / 9 . & \text { Region } I V
\end{array}\right.
\end{gathered}
$$


investment; for firms with $k_{1}^{A}>K_{A}^{\prime}\left(\gamma, k_{1}^{B}\right)$ or $k_{1}^{A}<K_{A}^{F C^{\prime}}$, their exploration investment does not change after the enforcement of the full-cost method.

In summary, in the Bertrand competition model, the result is the same as that in the Cournot market. 